University of San Diego

Digital USD

1994-05-01

\title{
Effects of Family Stress, Family Social Support, and Family Balance on Maternal Adaptation in Post Birth Families
}

Constance H. Blake Hansen DNSc, MN, RN

University of San Diego

Follow this and additional works at: https://digital.sandiego.edu/dissertations

Part of the Nursing Commons

\section{Digital USD Citation}

Blake Hansen, Constance H. DNSc, MN, RN, "Effects of Family Stress, Family Social Support, and Family Balance on Maternal Adaptation in Post Birth Families" (1994). Dissertations. 245.

https://digital.sandiego.edu/dissertations/245

This Dissertation: Open Access is brought to you for free and open access by the Theses and Dissertations at Digital USD. It has been accepted for inclusion in Dissertations by an authorized administrator of Digital USD. For more information, please contact digital@sandiego.edu. 
UNIVERSITY OF SAN DIEGO

Philip Y. Hahn School of Nursing

DOCTOR OF NURSING SCIENCE

\section{EFFECTS OF FAMILY STRESS, FAMILY SOCIAL SUPPORT, AND FAMILY BALANCE ON MATERNAL ADAPTATION \\ IN POST BIRTH FAMILIES}

by

Constance H. Blake Hansen, MN, RN

A dissertation presented to the

FACULTY OF THE PHILIP Y. HAHN SCHOOL OF NURSING UNIVERSITY OF SAN DIEGO

In partial fulfillment of the requirements for the degree DOCTOR OF NURSING SCIENCE

May 1994 


\begin{abstract}
Effects of Family Stress, Family Social support, and Family Balance, on Post Birth Maternal Adaptation
\end{abstract}

The purpose of this study was to describe the effects of perinatal family stress, family social support, and family balance on post birth maternal adaptation. The birth of a new infant is a transitional event that causes stress to the individuals within the family and the family as a unit. The chilabearing woman has been identified as the core of the expanding family. Her adaptive level is critical to the integration of the new infant into the family unit. Stress and support are important variables in maternal adaptation, yet the specific relationship of these variables as they relate to the family has not been adequately studied.

The study was a predictive correlational design. Subjects were 87 family units comprised of a childbearing woman and her identified significant other. Measurement of the variables occurred in the third trimester of pregnancy and at six to eight weeks post birth.

Hypotheses were designed to study the relationship of perinatal family social support, family stress, and family balance to post birth maternal adaptation. Descriptive, correlational, multiple correlational, and regression techniques were used for data analysis. Data for the family 
variables were analyzed using a family unit score based on the couple mean (Copland \& White, 1991).

An examination of the study hypotheses indicated that five of the seven hypotheses were supported. Family social support and stress were significantly correlated to post birth maternal adaptation prenatally, and family social support, stress and balance were all significantly correlated to maternal adaptation in the post birth measurement. When maternal adaptation was regressed on all independent variables, only family stress and family social support post birth were statistically significant $\left(\underline{N}=87, \underline{R}^{2}=.33, \underline{D}<.001\right)$. Further development of studies relating to how the family and new mother are enmeshed may help to establish more effective interventions for delivering care to this population. 
c Copyright 1994

$$
\text { V }
$$

Reproduced with permission of the copyright owner. Further reproduction prohibited without permission. 


\section{Dedication}

This work is dedicated to my husband Jim, who never lost faith in me; my children Bob, Mike, and suzanne for all the cookies they never received; my parents who taught me not to quit; and my sister vikki, a new mother, who helped in many ways but mostly by just being there.

vi 


\section{Acknowledgements}

While this has been for the most part a very lonely project, there are many people without whom it would have never been. First, I would like to thank the faculty and staff at Philip Y. Hahn School of Nursing, especially those who served on my committee: Dr. Perri Bomar - Chair, Dr. Rita Snyder-Halpern, and Dr. Patricia Roth. They have skillfully guided me through this process.

I would also like to thank Dr. Julie Johnson of the University of Nevada, Reno and Dr. Clarann Weinert of Montana State University for the mentoring I have received while completing this dissertation. Thanks to Dean Kathy Long, Mary Snepenger, Joann Barter, Sharon Delaney, Michelle Smith, and all the people at Montana State University College of Nursing who helped and encouraged me throughout this process.

And last but not least, a special thanks to Ketty Niemann of the University of San Diego who has always been cheerful and helpful and with whom I share a special bond.

vii 
Page

Abstract............................... ii

Copyright............................. v

Dedication............................ vi

Acknowledgements........................ vii

Table of Contents....................... viii

List of Tables......................... $x i$

List of Figures........................ xii

List of Appendices...................... xiii

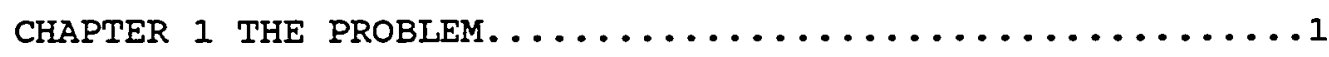

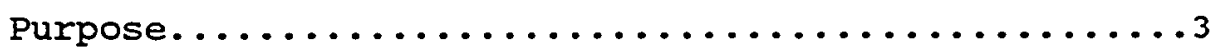

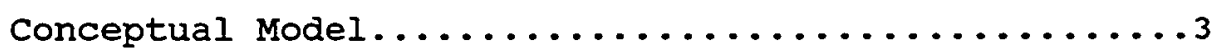

Hypotheses. ...........................

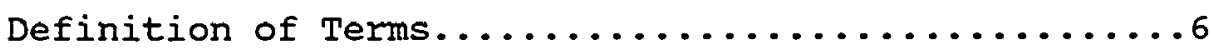

ChAPTER 2 REVIEW OF THE IITERATURE...............

Family Development Theory...............

Family stress...........................

Stress and the Perinatal Family........13

Social support and stress in Perinatal

Families...........................

Family Balance, stress and support in

Perinatal Families................20

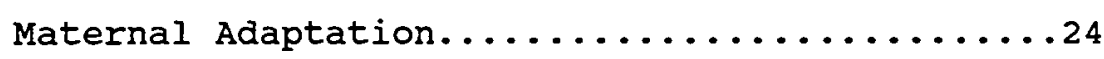

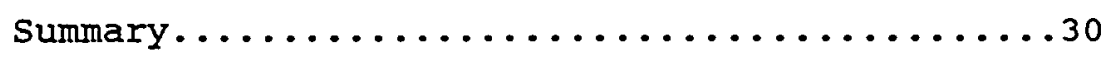

viii

Reproduced with permission of the copyright owner. Further reproduction prohibited without permission. 


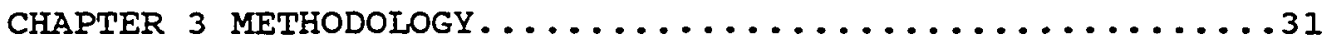

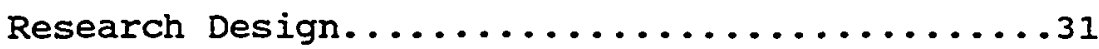

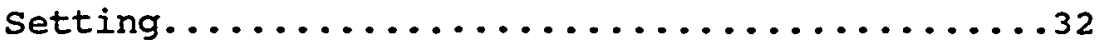

Sample............................

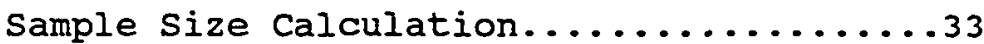

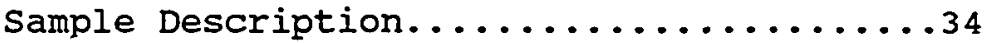

Instrumentation....................... 35

Demographic Forms.....................

FILE..........................

PRQ85 - Part 2.................40

FACESII.....................4I

PAS........................43

Data Collection Process................44

Data Analysis .....................

summary $\ldots \ldots \ldots \ldots \ldots \ldots \ldots \ldots \ldots \ldots \ldots \ldots$

CHAPTER 4 RESULTS........................ 46

Descriptive Data Analysis.............46

Hypothesis Testing.........................

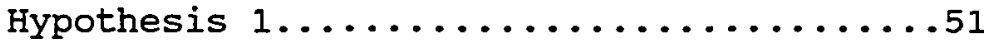

Hypothesis $2 \ldots \ldots \ldots \ldots \ldots \ldots \ldots \ldots$

Hypothesis $3 \ldots \ldots \ldots \ldots \ldots \ldots \ldots$

Hypothesis $4 \ldots \ldots \ldots \ldots \ldots 5$

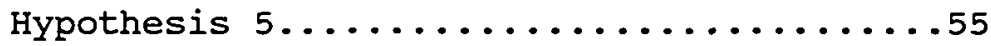

Hypothesis $6 \ldots \ldots \ldots \ldots \ldots \ldots$

Hypothesis $7 \ldots \ldots \ldots \ldots \ldots . \ldots \ldots 7$

Additional Data Analysis.................. 58

ix

Reproduced with permission of the copyright owner. Further reproduction prohibited without permission. 
summary.........................60

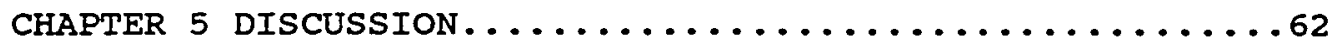

Discussion of study Findings.............62

Strengths and Limitations.............66

Implications for Future Research..........69

Significance for Nursing...............

Summary...........................

REFERENCES.............................

APPENDICES.............................

$\mathbf{x}$

Reproduced with permission of the copyright owner. Further reproduction prohibited without permission. 
Table

Page

1 Instrument Reliability..................44

2 Correlation of Predictor Variables with Post Birth Maternal Adaptation......................

$3 t$ - Test for the Independent Variables at Prenatal and Post Birth Measurement............50

4 Prenatal Individual and Dyad Mean Scores, Ranges, and Standard Deviations for PAS, PRQ85, FILE, FACESII.................... 52

5 Post Birth Individual and Dyad Mean Scores, Ranges, and Standard Deviations for PAS, PRQ85, FILE, FACESII.................... 53

6 Correlation Matrix of the Prenatal Independent Variables and Post Birth Maternal Adaptation......55

7 Correlation Matrix of the Post Birth Independent Variables and Post Birth Maternal Adaptation.....56

8 Stepwise Regression....................60 


\section{LIST OF FIGURES}

1. Hypothesized Model.......................

2. Regression of Predictor Variables................59

$x i i$

Reproduced with permission of the copyright owner. Further reproduction prohibited without permission. 
IIST OF APPENDICES

Appendix Page

Appendix A: Description of the Study Sample..........83

Appendix B: Prenatal Demographic Surveys.............85

Appendix C: Post Birth Demographic Surveys............92

Appendix D: The Family Inventory of Life Events and

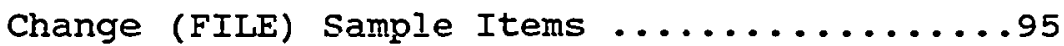

Appendix E: Personal Resource Questionnaire

(PRQ85) 85 - Part II Sample Items.........97

Appendix F: The Postpartum Adaptation Scale (PAS)

Sample Items...................98

Appendix G: The Family Adaptability and Cohesion

Evaluation scale (FACESII) Sample Items.....99

Appendix H: Human Subjects Approval...................

Appendix I: Childbearing Woman Consent..............10I

Appendix J: Significant other Consent............... 105

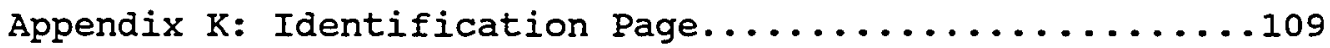

Appendix L: Letter of Explanation................110

xiii

Reproduced with permission of the copyright owner. Further reproduction prohibited without permission. 
CHAPTER 1

THE PROBLEM

In recent years there have been many societal changes that have altered the post birth environment for American families. The addition of a new baby changes the internal structure and function of families, while societal trends influence the external arena. Changes in the external structure of families may alter the level of stress in today's young families as well as the mother's ability to successfully adapt.

Family has been central to nursing practice since the time of Florence Nightingale. Today's nursing theories and standards reflect this centrality (Whall \& Fawcett, 1991). The first unit of social interaction for an individual is the family. The family is responsible for fundamental values and attitudes vital to the development of the next generation (Wakefield, 1984). Living within the context of family is becoming more complex and stressful for both the family as a unit and the individuals within the unit.

At no time during the childbearing family's development is family balance more stressed than following the birth of a new infant. Stainton (1989) defined post birth as an eight week period of time when the there is a reshaping of 
space, time, and interpersonal relationships that allow for individual and family tasks to be accomplished. This is a crucial time for the childbearing woman, infant, and the entire family. Not only are there physiological adjustments required of mother and newborn, there are also major psychological, relationship, role, and structural changes and adjustments required of the family unit.

Many childbearing women in today's society experience this crucial life transition to motherhood without adequate environmental supports. Whether these women are first time mothers or experiencing the birth of subsequent children, the integration of a new family member requires a period of transitional adjustment and adaptation that produces stress. The stress of integrating a new family member may be greater as the family is altered by changes in society and traditional family support systems no longer exist. Support is an important resource for coping with stress and influences the ability of the childbearing woman, as well as the childbearing family's ability to adjust and adapt (McCubbin, 1993).

The childbearing woman has been identified by Rubin (1984) as the core of the expanding family. Her adaptive level is critical to the integration of the new infant into the family unit. Barnard, snyder and spietz (1991) identified three key elements in the mother-infant interaction process. These were the mother's adaptive 
style, the child's temperament and adaptation, and the inanimate, animate and supporting environment. Support and the environment are clearly important variables in maternal adaptation and key in the all important interactive process between a woman and her infant. However, specific relationships between post birth maternal adaptation and family variables have not been adequately stuaied.

\section{Purpose}

The purpose of this study was to examine the effect of pre and post birth family stress, pre and post birth family social support, and pre and post birth family balance on post birth maternal adaptation.

\section{Conceptual Model}

The theoretical literature reviewed for the study connected transitional change to stress. Support has been identified as a resource for coping with stress. Adaptation to the life cycle transition of birth requires change for the family as a unit and for each individual member. This change results in situational stress (0lson, 1989). The amount of stress experienced by the family and the individuals within the family unit is dependent on both internal and external factors. The level of adaptation to this Iife cycle transition is Iinked to the amount of stress and the available resources of the adaptive system (McCubbin and Patterson, 1983). McCubbin (1993) identifies two phases of a family's response to life events and changes. These 
are the adjustment phase and the adaptation phase. Family adaptation is identified as the outcome of a family's effort over time to find a suitable fit for both the individual to the family and the family to the community. Adaptation is described as a continuum that ranges from bon adaptation to maladaptation.

The conceptual model for testing the hypotheses is illustrated in Figure 1. The model for this study views the both the family as a unit, and the mother as the crucial pivot of the unit, as adaptive systems. The amount of family stress and family support, as well as the degree of family balance, was established prenatally. It was hypothesized that both prenatal and post birth family stress, family support, and family adaptation would effect the level of post birth maternal adaptation. The level of family adaptation was measured as family balance.

\section{Hypotheses}

The following hypotheses were tested:

1. Prenatal family social support has a positive effect on post birth maternal adaptation.

2. Prenatal family stress has a negative effect on post birth maternal adaptation.

3. Prenatal family balance has a positive effect on post birth maternal adaptation.

4. Post birth family social support has a positive effect on post birth maternal adaptation. 
Figure 1. Hypothesized Model of the Relationships of Prenatal and Post Birth

Family Social Support, Family Stress, and Family Balance with Post Birth Maternal Adaptation.

\section{Prenatal}

Family Stress

Family Balance

Family Social Support

\section{Post Birth}

Maternal Adaptation

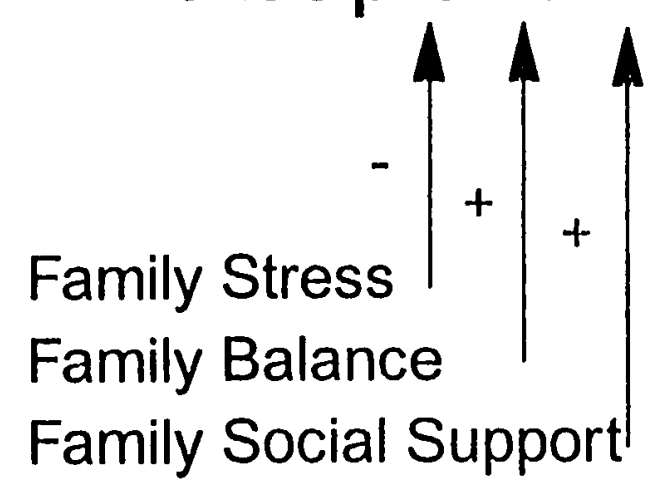


5. Post birth family stress has a negative effect on post birth maternal adaptation.

6. Post birth family social support has a positive effect on post birth family balance.

7. Post birth family social support, family stress, and family balance effect post birth maternal adaptation more than each individual family variable or the same combined variables in the prenatal period.

\section{Definition of Terms}

For the purpose of this study the following terms were defined:

Family: Two or more persons who are joined together by bonds of sharing and emotional closeness and who identify themselves as being part of a family (Friedman, 1992). Family stress: Family stress is a combination of stressors or demands, caused by major transitions or situational crisis the have the potential of changing the family system (Mccubbin \& Mccubbin, 1993).

Family social support: The relationship of the family to it's social system consisting of emotional, appraisal, instrumental, and informational components (Weinert \& Tilden, 1990).

Maternal Adaptation: The childbearing woman's feelings and responses post birth in the following areas: physical, emotional, role responsibilities, and caring for the infant (PAS, Nichols, 1988). 
The Post birth Period: The eight weeks after delivery during which there is a reshaping of space, time, and interpersonal relationships. It is during this time that family dynamics move from the infant as centerpiece to a widening of the social order (Stainton, 1989). Family Balance: The process occurring within family systems described by the behavioral dimensions of family adaptation, family cohesion. The most balanced families are the most functional (Olson, Portner \& Lavee 1985).

Summary

The problem outlined for study was the lack of available research describing how family phenomena is related to post birth maternal adaptation. The conceptual framework identified linkages between life cycle transitions, stress, and adaptation. The childbearing woman was described as a crucial pivot in the post birth family and support was identified as an important variable for families in adjusting and adapting to transitional changes such as birth. The variables were then defined for this study. In the next chapter an extensive review of the literature established the connections and gaps in the existing body of knowledge. 


\section{CHAPTER 2}

\section{REVIEW OF THE IITERATURE}

The variables of family social support, family stress, family balance and maternal adaptation post birth were investigated in this study. Previous research and related theories establish relationships among several of these study variables. The focus of this literature review was to critique those studies and theories that defined, related, and connected the study variables in perinatal families. Theoretical literature describing family development and family stress is discussed to identify the relationship between development, transition, stress, and support in young families. Finally, studies related specifically to family stress, social support, family balance, and maternal adaptation during the perinatal period are critiqued.

Family Development Theory

Many theories of family development view the process as linear. Duvall and Miller (1985) described eight life cycle stages of family development and the tasks involved in each. The second of those stages was childbearing. Carter and McGoldrick (1980) described only six life cycle changes. In this model the third stage was the childbearing family or family with young children. They identified key emotional 
processes, specific tasks, and second order changes that must be accomplished in order to meet the goals of the family and the individuals within the family. The degree to which these goals were met and tasks accomplished was the level of family functioning and adaptation (Carter \& MCGoldrick, 1980).

Combrink-Graham (1985) used a different approach and described family development as a spiral and not a linear process. This theoretical approach describes families as moving back and forth between periods of strong closeness and periods of more distance or disengagement. These periods are termed centripedal and centrifugal. Childbearing was described an example of a centripedal period when the family was enmeshed and typically very cohesive. Family members are drawn closely together to welcome the new infant and begin to identify and define the resulting new roles and relationships. The centrifugal periods are those times when family members were more disengaged. The launching of children is an example of a centrifugal period. As the children move out to begin their own life there is a disengagement of the nuclear family and a re-negotiation of the marital dyad.

The Circumplex Model of Family systems as described by olson (1989) allows for the integration of systems theory and family development theory. Olson maintained that 
families must change as they adapt to normal life cycle transitions.

\section{Family Stress}

Family stress occurs as a result of major transitions or situation crisis. It is defined as a "pile-up" of stressors that have the potential of producing changes in the family system (McCubbin and McCubbin, 1993). The earliest examination of family dynamics under stress resulted in the $A B C X$ model of family crisis developed by Hill (1949). In this classic model the stressor (A) in association with the family resources for meeting the stressor (B) and the family's interpretation of the stressor (C) affect the family response (X) in terms of amount of distress and the family's methods of coping with the stressor (Olson \& McCubbin, 1982). Stressor was defined "as a life event impacting upon the family unit which produces or has the potential of producing change in the family social system" (McCubbin \& Patterson, 1983, p.7). The refinement of this model resulted in the T-Double ABCX Model of Family Adjustment and Adaptation described by McCubbin and McCubbin (1991). This model discussed families in two related but different phases as they respond to life changes and crisis. Theses phases are the adjustment phase and the adaptation phase.

The adjustment phase for the childbearing family was described as the attempt of the family system to cope with 
the transitional crisis that resulted with the addition of a new family member. The adaptation phase for the childbearing family was the time when the family attempted to recover from the transitional crisis of childbearing and integrate the new baby into the family system. This required the family to reorganize and change its structure and function to meet the demands of having a new family member.

Mccubbin and Patterson (1983) hypothesized that families are seldom confronted with only one major stressor at a time, and an accumulation of stressors or "pile-up" was a key factor in predicting the family's adaptation to a stressful event. McCubbin and Mccubbin (1993) refined this concept and developed the Resiliency Model of Family stress, Adjustment and Adaptation. In this model, they define family resiliency as "the ability of the family to respond and eventually adapt to the situations and crises encountered over the family lifecycle" (Mccubbin, 1993, p. 47). This latest model added family types as basic strengths of the family unit, family problem-solving, and a hڤ̈gher level of family appraisal and meaning as critical factors in family adaptation (McCubbin, 1993). The Resiliency Model presented three levels of family appraisal. The three levels were the family's appraisal of stress, the family's definition of their resources and capabilities and the global level of appraisal based on the family beliefs, 
values, shared identity, and goals (McCubbin, McCubbin and Thompson, 1993). Family stress theory was described as the scholarly attempt to explain why some families were able to adapt to transitions and crisis and others, when faced with the same situations, were easily exhausted. This theory was based on the premise that family type, family strengths, and family resources buffer the negative impact of change or unexpected Iife events (McCubbin \& McCubbin, 1991).

Family stress was the basis for a study by Lavee, McCubbin and Olson (1987). They used a multivariate path model to study the effect of stressful life events and transitions on family functioning and well-being. Data from I,140 families were analyzed using LISREL VI. They found both stressful life events and transitions influenced the amount of intra-family strain accounting for $7 \%$ of the variance. Family strain was shown to have a negative impact on marital adjustment and family well-being $(\underline{r}=-.68 \&$ -.28) respectively; $p>.05)$. Both a sense of coherence and marital adjustment were positively related to family wellbeing ( $\underline{r}=.45 \& .21 ; \underline{p}>.05)$. The results of this study indicated that family strains more than the transitional event predict a decrease in family well-being. The study looked at families in all stages of development and cannot be generalized specifically to post birth families. 
Stress and The Perinatal Family

Stress and the perinatal family was discussed in a study conducted by Laizner \& Jeans (1990). They used a descriptive correlational design to identify predictor variables of a postpartum emotional reaction. In this study of 27 women $59 \%$ reported some degree of depression postpartum. They found that stress related to loss of control, prenatal depression, and low health status accounted for $52 \%$ of the variance in postpartum maternal depression. The study did not analyze maternal post birth depression in relation to either maternal or family adaptive levels.

Affonso and Mayberry (1990) studied 221 women during pregnancy and postpartum to identify stressors common to childbearing women and quantify their intensity. The most frequently reported stressors were physical distress, concerns about body image, and concern about the baby. The most intense stressors were concerns about the baby, physical distress, and difficulties in the relationship with the baby's father. They also noted that stressors changed in both frequency and intensity as the woman moved through the pregnancy into postpartum. Physical stressors were of more concern during pregnancy, while relationships and economic stressors were of more concern postpartum. The study was developed as a pilot study to identify stressors 
and no attempt was made to relate the stress to the family or to maternal adaptive levels.

Mercer \& Ferketich (1988) studied four groups; 153 high-risk women, 75 high-risk partners, 218 low-risk women, and 147 low-risk partners during the 24 th to 34 th weeks of pregnancy. The purpose of this study was to identify the effects of antepartum stress on anxiety and depression in high risk and low risk couples. Stress was defined as negative life events and measured using Norbeck's 1984 adaptation of the Iife Experiences Survey by Sarason, Johnson, and siegel. They used a predictive correlational design to test their hypotheses. The results indicated that, while there were no gender differences for stress, the high risk women reported more received support, $(\underline{t}(67)=$ $5.51, \underline{p}<.001)$; perceived support, $(\underline{t}(73)=2.91$, $\underline{\mathrm{p}}<$ $.005)$; lower sense of mastery, $(\underline{t}(73)=-2.74, \underline{p}<.008)$; and higher depression $(\underline{t}(73)=3.10, \underline{p}<.003)$, than their mates. The low-risk pairs reported similar results. This study examined individual differences in stress, and measured stress as "perceived impact of negative life events and a pregnancy risk score" (p. 27). The work did not discuss the concept of family stress or the effect of an accumulation of stressors on the family unit.

The Iiterature related to stress and families indicated that the accumulation of stressors is a key variable in family adaptation (McCubbin \& McCubbin, 1991). Studies 
related to perinatal families showed that regardless of gender, stress was important in predicting the health and well-being of individual family members during pregnancy. No work.specifically related family stress to maternal adaptation in post birth families. Stress and Social support in Perinatal Families

The literature revealed social support was an important variable in reducing the stress for families during the post birth period. Social support and stress studies also identified relationships between various variables associated with maternal adaptation and support. The construct of social support was described as multidimensional and four major components were identified. The components were emotional support, appraisal support, informational support, and instrumental support. Social support was also described in terms of action, as the ability to prevent or buffer stress and have a direct positive effect on health (Weinert \& Tilden, 1990).

Turner and Avison (1985) used a multiple discriminant function analysis design to compare adaptive and maladaptive mothers two to four weeks after delivery. They found that social support correctly classified $93 \%$ of the total group in terms of adaptation or maladaptation. A strong canonical correlation of .75 also attested to the discriminate power of this variable. There was no attempt to associate either 
social support or adaptation to family stress or family balance.

Dormire, Strauss and Clarke (1989) used a correlational design to study the relationship of social support to maternal adaptation in 18 primiparous adolescent mothers. They found that parent-infant interaction was positively related to social support $(\underline{r}=.59, \underline{p}<.01)$ and parental sense of competence was negatively correlated $(\underline{r}=-.69$, $\underline{p}<.001)$. While relationships between parenting behaviors and social support were identified, the sample was too small and homogeneous to generalize the results.

Capuzzi (1989) used a descriptive correlational design and employed multiple regression statistics to examine the relationship of social support to the attachment process in mothers with and without handicapped infants. She found that social support prenatally was significantly related to postpartum attachment in mothers with handicapped infants $\left(\underline{R^{2}}=.43, \underline{F}(4,16)=4.80 ; \underline{p}<.01\right)$. The researcher speculated that the presence of social support helped to reduce the stress of having a handicapped infant. This study described one function of maternal adaptation and did not attempt to associate family with the other study variables.

One study examined stress and social support in relation to marital and parental satisfaction. Pittman \& Lloyd (1988) used a causal model to study 810 families and 
found that stress negatively affected both parental and marital satisfaction, but social support reduced the effect of the stress. The most powerful negative influence was stress in the home life which was significant at the .001 level. They noted that stressors were two to four times stronger when predicting marital and parental satisfaction than were resources and supports. They did find that resources and supports were significant in reducing the effects of stress $\left(\underline{R^{2}}-\right.$ change $\left.=0.169, \underline{E}=38.5, \underline{p}<.001\right)$. This study looked at families in all stages of development and did not regard family stage in data analysis.

In a correlational study Crockenberg and McCluskey (1986) studied 48 mother infant pairs when the infants were 3 to 12 months of age. The purpose of this study was to identify the potential influence of maternal attitudes, social support, and infant irritability on maternal behavior. They found social support positively related to changes in maternal responsiveness to her infant from 3 to 12 months post birth $(\underline{r}=.32, \underline{p}>.05)$. The researchers did not consider the effect of social support during the perinatal period nor did they relate maternal behavior to the family variables. The relationship of support to maternal responsiveness did suggest that social support was an important variable to study when the research question involved maternal behavior related to role adjustments. 
Role adjustments, in terms of infant caretaking activities as it related to social support, was also studied by Kaufman and Hall (1989). They conducted a prospective analytic study to examine influences of the social network on the choice and duration of breast-feeding among 125 mothers of preterm infants. Mothers who chose to breast feed had mean scores of $56.3(\underline{S D}=34.2)$ on the Influence of Specific Referents Scale, as opposed to bottle feeding mothers whose mean scores were $1.3(\underline{S D}=19.7)(\underline{p}<.001)$. This relationship suggests that mothers who chose to breast feed their preterm infants were much more likely to perceive that significant people in their social network; including the infants father, health care professionals, and her own mother approved of the breast feeding. Bottle feeding mothers conversely indicated they perceived their social network as neutral. Supports for breast feeding were also significantly related to duration $(\underline{p}<.001)$. When mothers who reported no supports were compared to mothers who reported supports they were six times more likely to cease breast feeding. This study related only to the feeding caretaking activity but does suggest that support is an important variable.

Brown (1986) used a predictive correlational design to study the influence of social support and stress on the health of expectant mothers and fathers. In her sample of 313 she found that stress was negatively related to health 
in both the expectant mother $(\underline{r}=-.41)$ and expectant father $(\underline{x}=-.20)$ but the significance level for mothers was much greater than for the fathers. Satisfaction with partner support was a significant balance for both (fathers - Beta = $.38, \underline{p}<.001 ;$ mothers - Beta $=.19, \underline{p}<.002)$. Regression analysis also indicated that stress and support were more important variables explaining health status for expectant mothers $\left(\underline{R}^{2}=.30 \mathrm{p}<.001\right)$ than for expectant fathers $\left(\underline{R}^{2}=\right.$ $.17 \mathrm{p}<.001)$. This study looked at only scores of the individuals and did not attempt to analyze the family as a unit. Neither did the study describe any of the variable relationships post birth.

Social support was identified as an important variable in buffering stress and predicting maternal adaptation. Postpartum attachment in mothers with handicapped infants, parental satisfaction, maternal role adjustment, and breast feeding were also influenced by social support. Most of the research mentioned above studied mothers and social support. A few studies included fathers, but the concept of social support was studied only as perceived by the individuals. None of the existing research described how social support, maternal adaptation, and family balance are related. No attempt was made to study social support as a family variable. 
Stress, Support, and Family Balance in Perinatal Families

Transitions were shown to be stressful to families and the transition to parenthood is no exception. Hill and Mederer (1983) noted that families must change their rules of interrelating each time a member was added to the family. They proposed that research to describe the manner in which families reorganize to establish equilibrium was paramount to the understanding of families.

Family balance in this study was conceptualized on the basis of the Circumplex model of Family systems. The model was developed to delineate critical dimensions of family dynamics and evolved as an effort to explain family dynamics in the face of stress. Olson (1989) hypothesized that families change their adaptability and cohesion as they adjust and adapt to the stress. Assessment based on this model resulted in three general family types; balanced, midrange, and extreme. Family functioning was measured by the degree to which the family was balanced. Balanced families function more adequately than extreme families and thus have a higher adaptive level (Olson, 1989).

Several studies were reviewed that looked at family dynamics during the childbearing period. olson, Lavee, and Mccubbin (1988) studied families across the life cycle to identify family types at different stages of development, as well as perceived well-being. They found families who were in the childbearing years to be structured and connected. 
Families during this period were not very flexible but were relatively cohesive. They had rigid roles and role relationships and were strongly bonded to one another. The family members at this stage of the family life cycle had less individual autonomy than did family members at other stages in the family life cycle. They rated higher in terms of well-being than families with older children at home, but families with no children at home were more satisfied.

Lewis (1989) studied the relationship between prenatal marital competence, and parenting skills and attitudes at three months postpartum. He found that marital competence influenced both parents attitudes and parenting skills. The most striking finding in this study was the evidence that when the husband was more satisfied prenatally, wives were more invested in and warmer toward the child.

Nurse researchers have examined childbearing and the family in terms of family functioning, parent coping, and parent expectations. Mercer, Ferketich, DeJoseph, May, and Sollid (1988) tested a causal model to predict family functioning in both high and low risk pregnancies. In their sample of 593 individuals consisting of pregnant women and their partners, they found the high risk couples perceived a greater discrepancy in family functioning than did the low risk couples. For the high risk women a sense of mastery was the major predictor of family functioning explaining $17 \%$ of the variance. The partners of these women indicated that 
social support was the key predictor of family functioning explaining $32 \%$ of the variance. Low risk women identified depression as the key predictor of family functioning accounting for $13 \%$ of the variance. Support was the major predictor for the low risk partners accounting for $23 \%$ of the variance.

Mercer and Ferketich (1990) used a causal model to explain family functioning eight months following birth in the same group of high and low risk couples studied prenatally. They found that $58 \%$ of the variance in family functioning at 8 months postpartum for high risk women could be explained by depression, social support, and negative life events in the early postpartum. In the low risk group, $38 \%$ of the variance was explained by depression, health perception, social support, parent attachments, and negative life events. Variables showing direct effects for high risk men were state anxiety and partner pregnancy risk. These accounted for $50 \%$ of the variance in family functioning at 8 months postpartum. Low risk men indicated that perceived support in the early postpartum, medical treatment for pregnancy health problems, and the relationship with their own fathers were significant, accounting for $33 \%$ of the variance.

These studies indicated that stress and social support were important indicators of family balance in childbearing couples regardless of pregnancy risk. Neither the prenatal 
nor the post birth analysis of this model related maternal adaptive levels to post birth family balance.

other related research studied parent coping and role expectations in relation to management of family tasks. Parent coping two to three months postpartum was studied using a correlational design by Ventura (1986). Coping patterns were grouped into four pattern groups. These pattern groups were identified as: seeking social support and self development; maintaining family integrity; being religious, thankful, and content; and being responsible. Significant correlations were identified between infant temperament variables and all coping patterns for both mothers and fathers. Mothers found social support and selfdevelopment more helpful than did fathers $(\underline{t}=4.69$, $\mathrm{p}<.001$ ). This study found that both parents tended to cope in a similar manner and that infant temperament was an important variable in family adaptation. Optimal coping for new parents in this study involved the couples whose actions were directed at anticipating and managing family tasks. There was no attempt to correlate maternal adaptation with coping or family functioning.

In another correlational study, Humenick and Bugen (1987) studied the differences in role expectations and the realities of parenting for 37 middle class couples. They found that prenatal expectations were often very different from postpartum realities. Mothers expected to spend less 
time parenting than they actually did $(\underline{\underline{r}}=.78, \underline{\mathrm{p}}<.001)$ and fathers expected to spend more $(\underline{r}=.51, \underline{p}<.001)$. There was no attempt to relate these expectation differences to maternal adaptation or the family.

Literature related to family functioning, family balance, support, and stress in perinatal families indicated that the addition of children added stress and decreased family satisfaction. The level of satisfaction influenced family balance and attitudes of family members toward the children. It was also noted that while new parents tended to cope with the stress in similar ways, prenatal parent role expectations were very different from the post birth realities in terms of who actually spends time parenting. No studies examined the effect of added stress and support on family balance or maternal adaptation.

\section{Maternal Adaptation}

Maternal adaptation requires physical, emotional, and role adjustments that interrelate and are equally important. When these adjustments can be successfully achieved the result is physical restoration, emotional stability, return of functional ability, and integration of maternal identity (Rubin, 1984). Maternal adaptation was measured in terms of physical and psychosocial adjustment to the role of being a new mother. It was viewed as a role assumption (Rubin, 1967; Mercer, 1981; Walker, Crain, \& Thompson, 1986) and return of functional ability (Tulman \& Fawcett, 1988). 
Literature that explored maternal adaptation in relation to physical health, emotional health, functional ability, and role adjustments post birth was reviewed.

In a descriptive study of 40 new mothers, Gruis (1977) described four tasks a postpartum mother must accomplish. These were physical restoration, learning to care for and meet the needs of a dependent infant, establishment of a relationship with the infant, and alteration of lifestyle and relationships to accommodate a new family member. She found that the primary concerns of these women related to physical restoration (95\%) and alteration of lifestyle and relationships to accommodate a new family member (90\%). She also noted that primipara's concerns focused on the newborn and multiparas identified the strain that a new child places on the rest of the family as a primary area of concern. Both physical adjustments and the impact of the birth on the rest of the family were of concern to these subjects. This was an early descriptive study in which, neither the design nor the analysis in this study was particularly rigorous, but it was valuable in identifying areas of concern in postpartum women.

Pridham (1987) explored the meaning of having a new infant with 83 mothers of healthy newborns. She used a descriptive design to examine variables related to difficult factors, satisfying factors, difference having a new baby made, and what would make things better. Significant $\underline{F}$ 
values for personal development and competence identified a positive relationship with difference having a new baby made $(\underline{p}<.001)$ and difficult factors $(\underline{p}<.01)$. Mothers in this study identified that when they felt competent and had a sense of personal development having a new baby made little difference in quality of life. When they felt incompetent and had no sense of personal development, scores related to the variable, difference having a baby made, were higher. The same held true of difficult factors. Another significant finding in this study was the positive relationship of time to the category what would make things better $(\underline{p}<.05)$. This study identified role adjustments and time as areas of concern for new mothers after giving birth. Researchers of post birth maternal adaptation also describe variables related to maternal functioning. Tulman and Fawcett (1988) contended that the goals of physical restoration should include more than the classic medical focus on the healing of the reproductive organs. They also maintained that this process potentially took longer than the traditional six weeks. These authors discussed the return of functional ability, not physical healing as an indicator of maternal wellness and adaptation. Functional ability was described as the resumption of household, community, social/occupational activities, and assumption of infant care activities. They studied 70 women in a descriptive correlational study and found that only $51 \%$ had 
regained their normal energy level at six weeks postpartum. Women who experienced cesarean delivery (70\%) where much less likely to regain normal energy at six weeks postpartum than were those who delivered vaginally $(34 \% ; \underline{p}<.01)$. This study also revealed that those who experienced a health complication postpartum were significantly less likely to return to work ( $\underline{0}<.04)$ than those who remained without complications. There were no significant differences between primiparas and multiparas in return of functional ability. Neither support nor the relationship between functional ability and family functioning was studied.

Affonso (1987) discussed many of the same activities mentioned in Tulman and Fawcett's work. She defined them as indicator activities and viewed perceived inability to meet these obligations as a stress factor that influenced maternal affect. Her sample consisted of 80 subjects who completed questionnaires related to postpartum adaptation and depression at three and eight weeks postpartum. A descriptive design was used and statistically significant relationships were noted between the stress factors and maternal depression using Pearson's $r(\underline{p}<.05)$ at both the three and eight week periods. The study only attempted to identify stress producing areas for the postpartum mother. It did not examine the relationship of social support, family stress, or functioning to maternal adaptation. 
Flagler (1990) used a descriptive correlational design to determine relationships between statements of 20 postpartum women about how they felt and about their maternal adjustment. She found that $80 \%$ of these women used negative terms to describe the way they felt physically four to six weeks postpartum. She further noted that the negative descriptors significantly correlated to scores on mother-infant mutuality $(\underline{\underline{r}}=-.72, \underline{\underline{p}}<.001)$ and maternal anxiety about rearing a child $(\underline{\underline{r}}=-.47, \underline{p}<.05)$. These negative correlations denoted that mothers who described themselves in negative terms physically were more anxious and reflected less mutuality with their infants. Those mothers who described themselves in negative terms emotionally showed a less positive relationship with their husbands $(\underline{r}=.68, \underline{p}<.001)$, less general satisfaction with Iife $(\underline{r}=.59, \underline{p}<.01)$, and less support for maternal role from family and friends $(\underline{r}=.63, \underline{p}<.01)$. The results of this study would be stronger if the sample size was larger. However, there was demonstration of a relationship between maternal adaptation and physical variables, perception of support, and spousal relationships. A correlation between family stress, family functioning, and adjustment was not reported.

Curry (1983) used a descriptive factor-relating design to examine, in 20 primiparas, the relationship of maternal adaptation to self-concept, age, socioeconomic status, 
support systems, and previous experience with infants and children. She identified $25 \%$ of her subjects as difficult adapters and noted that those women scored a significantly lower on the Tennessee Self-Concept scale than did the easy adapters. Curry also noted that difficult adapters tended to demonstrate fewer maternal attachment behaviors toward their infants three months post delivery than did women who described adaptation to motherhood as easy. Although the sample was small the study did show a relationship between adaptation, self-concept, and maternal attachment behaviors. There was a wealth of research related to maternal adaptation and variables associated with identification of adaptation. These studies indicated that maternal adaptation was more than a physical healing process, but was also related to maternal self-concept, significant relationships, and functions of the maternal role. The research also described concerns of new mothers and stressors. The physical, emotional, and role function aspects of maternal adaptation have been established, but there is a void in the literature relating maternal adaptation and support to the family. 


\section{Summary}

The literature substantiated that the addition of a new baby is a stressor in families. Family adaptation related to the transitional crisis of birth may be related to many different variables. Family functioning is an indicator of family adaptation. Balanced families are considered bon or highly adaptive and extreme families maladaptive. There is evidence that the addition of children negatively influences marital satisfaction, family satisfaction, and perceived quality of life. There is also evidence that all family relationships are influenced by and influence the parenting process. The postpartum period is crucial to the development of parenting roles. Studies suggest that maternal maladaptation leads to the inability of the childbearing woman to assume her role in the family. Social support is significant in reducing stress, improving both individual and family adaptive levels, and is perceived as helpful by the families. The relationship between family social support, family stress, family balance, and maternal adaptation has not been directly studied. 


\section{CHAPTER 3}

METHODS

This chapter contains a discussion of the research methods. First, the study design itself is identified. Then the sample, measurement, and data collection are outlined. Finally, the methods used in data analysis are addressed.

\section{Research Design}

This study was designed to examine the effect of perinatal family stress, family social support, and family balance on post birth maternal adaptation. The literature review established predictable and credible relationships among stressors, supports, and adaptive responses in perinatal families. Although a relationship was credible and predictable, existing data did not indicate causality. Neither the Iiterature review nor the conceptual framework warranted an attempt to infer causality or manipulate the identified variables. Therefore, the appropriate design for this study was a predictive correlational design (Waltz \& Bausell, 1981). The conceptual model and hypotheses were consistent with the study design and appropriate multivariate statistics were used for data analysis, thus 
protecting the internal validity of the study (Krathwohl, 1985).

\section{Setting}

The sample for this study was recruited from two states in a mostly rural setting. The majority of the subjects, 80 families, were recruited in the rural state of Montana. The remaining seven families came from a suburban population in Western Washington. Montana is the fourth largest state in size but has a total population of only 800,000 people. Thus the entire population of the state is considered rural.

\section{Sample}

A sample of childbearing couples that met the criteria for family as defined for this study was selected from the previously described setting. The sample was a non probability convenience sample of 89 families which were recruited from childbirth education classes. Montana subjects were recruited from both private and hospital based childbirth education classes in the state's four major population centers. These communities represent the eastern, western, northern, and southern sections of the state and are separated by 360 miles east to west and 200 miles north to south. The western washington families were recruited from hospital based childbirth education classes.

Childbirth classes were offered for pregnant women in the third trimester of pregnancy and their labor support person. Researcher access to the classes was achieved 
through independent childbirth educators and childbirth education departments in hospitals and prenatal clinics in Montana and western Washington.

For analysis, two of the 89 families recruited were excluded from the study because the significant other in the first measurement appeared to be a different person than the significant other in the second time measurement. Each subject family $(\underline{n}=87)$ was a dyad comprised of a childbearing woman and her identified significant other. Criteria for inclusion in the study were as follows: both a mother and a significant other who was 18 years of age or older and spoke, understood, and read English; and the mother to be was a woman in the last trimester of a nonmedically complicated pregnancy that resulted in a physically healthy mother and infant post birth. The significant other was identified by the participating childbearing woman as: a) the person most involved with her pregnancy, b) the person who would be most involved with her and the infant post birth, and c) remain the same person for the duration of the study.

Sample size calculation. The power analysis criteria used to determine appropriate sample size for this study was outlined by cohen (1987). Using Cohen's criteria for multivariate data analysis, the power was calculated for this sample. The actual alpha was .05, with a large effect, size and $n=87$. This resulted in a power of .995 (Cohen, 
1987, p. 320), well above the minimum acceptable power of .80 (Cohen, 1987).

Sample Description. The age of the childbearing women ranged from 19-39 with a mean age of 28 and the significant other ranged from 21 to 48 with a mean of 32 . The sample was $97.6 \%$ Caucasian with a mean income category of $\$ 35,000$ to $\$ 39,999$ annually. Thirty-seven percent of the sample stated they had an annual income below $\$ 25,000$. The mean number of years of education for both the mother and significant other was approximately 15 years. Ninety percent of the families who participated in the study were married couples. Ninety-three percent of the significant others were the fathers of this infant. Ninety-six percent of the significant others reported that they were employed at the time of the first measurement which remained fairly constant throughout the study with $93 \%$ reporting to be employed post birth. of the childbearing women, $70 \%$ stated they were employed before the birth of the baby and $56 \%$ reported that they were still employed six weeks post birth. For $76 \%$ of the families, this was the first child and a second child for another $21 \%$. Seventy-six percent (76\%) of the women were breast feeding at the second time measurement.

In summary, the sample was primarily Caucasian, educated beyond high school, and middle class. The families were mostly traditional married couples having a first or 
second child. Most of the significant others were employed as were many of the childbearing women. The majority of the childbearing women in the sample continued to breast feed six to eight weeks post birth. The sample is described in detail in Appendix $A$.

\section{Instrumentation}

Measurement of the variables was achieved using six paper and pencil tools for each mother and five for each significant other. The instruments included: an investigator designed Prenatal Demographic Survey for each mother and her identified significant other (see Appendix B), an investigator designed Post Birth Demographic Survey for each mother and her identified significant other (see Appendix C), The Family Inventory of Life Events and Change (FIIE) developed by Mccubbin, Patterson and wilson (1981) (see Appendix D), Personal Resource Questionnaire (PRQ85) Part 2 developed by Brandt \& Weinert (1981) and Weinert (1987) (see Appendix E), the Postpartum Adaptation Scale (PAS) developed by Nichols (1988) (see Appendix F), and the Family Adaptability and Cohesion Evaluation Scale (FACESII) developed by Olson, Portner \& Bell (1982) (see Appendix G) .

The total anticipated time commitment for completion of these instruments was established in a pilot study of five mothers and their significant others. Education level of all pilot pairs varied from 12 to 16 years. The prenatal 
package took 20 to 30 minutes for each participant. Postpartum packets took 20 to 30 minutes for the significant others and 35 to 55 minutes for the mother. Total subject time commitment for the entire study was approximately one hour for the significant other and one hour and 30 minutes for the mother.

The Demographic Forms. Two demographic forms were completed by each mother: one prenatal and one post birth. The identified significant other also completed two different forms: one prenatal and one post birth. The forms were reviewed by a panel of five content experts in perinatal nursing for face validity. As the intent of these forms was to describe the sample and assure that all family members met the study criteria in both measurements, no content validity index (CVI) scores or reliability indexes were calculated (Waltz, Strickland \& Lenz, 1986). The prenatal demographic forms contained 18 short answer or categorical selection items for the childbearing woman and 16 for her significant other. The questions were designed to obtain information related to: age, gender, relationship to the infant, marital status, number of family members living in the household, family composition, cultural and ethnic background, income, employment status, and employment leave plans after the birth. In addition, the childbearing woman was asked to provide data relative to 
her obstetrical history and expected date of delivery (see Appendix B) .

The post birth demographic forms contained eight items in the same format as the prenatal questions for the childbearing woman and seven for her significant other (see Appendix C). The post birth forms were used to collect data related to the infant, infant feeding method, and employment status post birth. The post birth forms also served as verification that the post birth significant other was the same person that was identified in the prenatal measurement. The four demographic forms were designed to describe individual study participants and provide primarily nominal level data. It took 10 minutes to complete the prenatal version for each individual and five minutes for the post birth form.

The Family Inventory of Life Events \& Changes (FILE). The FILE was selected because of its congruence with the conceptual framework of the study, ability to operationalize family stress, and relative ease to administer and score. It is a 71 item "Yes" or "No" self report scale providing nominal level data, that was developed to assess the pile-up of events experienced by a family in the last year (see Appendix D). FILE was completed by each individual and provided an index of family vulnerability resulting from these stressors. The instrument also contains 34 items which were designed to assess changes and life events prior 
to the last year. These events frequently require more than one year for adaptation or are chronic stressors (McCubbin and Patterson, 1991).

FILE took 15 minutes to complete and was scored by using a weighted sum of the total number of "Yes" answers. "Yes" answers were coded with a weighted numerical value and "No" answers as 0 . A higher score indicated more stress. This scale was administered to 1140 couples in seven different Iife cycle stages and proved to be useful at all stages (McCubbin \& Patterson, 1991).

Content validity was established by a panel of experts based on clinical and research experience. The instrument authors did not calculate a content Validity Index (CVI) . Construct validity was established using factor analytic procedures with an oblique rotation to determine the underlying dimensions. Using only factor analysis to determine reliability, the reliabilities of the subscales ranged from .73 to .30 . An acceptable level of total scale reliability $(\underline{\alpha}=.81$ ) was supported using a sample of 2740 participants. Test-retest reliability scores ranged from .72 to .77 within Nunnally's (1978) criteria for acceptable reliability over time (Mccubbin \& Patterson, 1991). The authors of FILE warned that while the scales for FIIE were created on the basis of factor analysis, they were not to be used alone as a reliable indices of stress. The instrument was designed to measure stress throughout the family life 
cycle and the authors noted that different factors produce stress during each life cycle stage making the alpha's on the subscales lower or higher relative to the life cycle stage of the family (McCubbin \& Patterson, 1991). Mccubbin and Patterson (1991) reported that the construct validity of the FILE was also supported by correlating it to a measure of family functioning by Moos (1974). The hypothesis that a pile-up of life changes would negatively correlate with desirable dimensions of family environment (cohesion $=-.41$, expressiveness $=-.19$, independence $=-.26$ and organization $=-.21$ ) and positively correlate to undesirable characteristics of the family environment (conflict $=.42 \&$ control $=.14$ ) was supported.

cronbach's alpha coefficients for this study were calculated for each of the nine FILE subscales and the total scale. As found in previous research many of the subscale alpha's were low. Subscale alpha's were: Intra-Family Strains $=.68$, Marital strains $=.42$, Childbearing Strains $=.15$, Finance strains $=.49$, work/Family Transitions $=.67$, IIlness Strains $=.34$, Losses $=.14$, Transitions $=.32$, and Family Legal Violations $=.91$. If the criterion of 5 subjects per item outlined by Tinsley and Tinsley (1987) are applied then the $\underline{n}$ for each subscale is appropriate. The total scale reliability for this study was an acceptable .83 (Nunnally, 1978). Based on the recommendations of the authors of FILE and because of the 
low subscale reliabilities, FILE was used only as a total scale for data analysis.

Personal Resource Questionnaire 85 (PRQ85) - Part 2.

The PRQ85-Part 2 was chosen for this study to operationalize social support because the tool was succinct, easy to administer, and had been evidenced valid and reliable (see Appendix E). This tool was a refinement of the PRQ developed by Brandt \& Weinert (1981). The current tool was described by weinert (1987) as a self administered two part instrument. Part 2 of this scale was a Likert - type seven point scale that was designed to measure an individual's perception of global social support and took approximately five minutes to complete. The PRQ85 Part 2 was scored by reversing the order of items $d, g, j, p$, and $x$, then summing all item scores. Higher scores indicated greater perceived individual social support.

Validity for Part 2 of the PRQ85 was judged by a panel of expert researchers in two studies. No CVI was calculated. Construct validity was established using a multitrait-multimethod approach. Convergent validity correlations were evaluated between Part 2 of the PRQ85 and five other social support scales. The PRQ85 part 2 correlated significantly with all 5 of these social support scales. In three recent studies the alpha coefficients ranged from .87 to .90 indicating a high degree of internal consistency reliability (Weinert, 1987). The PRQ85 used 
with childbearing families has also demonstrated reliability with an alpha coefficient of .88 (Weinert, 1987). A family social support score was calculated using a mean score for each family pair. The current study was the first to use the PRQ85 as a family measure but using the family as a unit of analysis did not decrease the reliability. The total scale alpha for this sample was .91 .

The Family Adaptability and Cohesion Scale (FacesII). FACESII was selected for this study because of its ability to operationalize family balance as bon adaptation which is consistent with the conceptual framework of the study. The instrument was designed to measure family dynamics and focuses on all family members currently living at home (Olson \& Tiesel, 1991). The items are constructed as statements regarding the perception of an individual family member about his/her family. The instrument is constructed on a Likert-type scale and provides ordinal level data. This instrument has been administered to thousands of American families in several hundred different studies and is appropriate for families at all stages of development, from newly formed families to those in the retirement years. The FACESII is a 30 item self-report tool measuring family balance with two subscales; family adaptation and family cohesion (see Appendix G). It took 5 to 10 minutes to complete. The FACESII was selected in lieu of FACESIII upon the recommendation of Dr. Olson (personal 
communication, September 26, 1991) because of its more acceptable psychometric properties. Construct validity has been established through factor analysis. There are 16 items for the cohesion subscale and 14 for the adaptability subscale. Alpha for family cohesion was .87 and family adaptability .78 (Olson \& Tiesel, 1991). The alpha coefficients indicated that the instrument had an acceptable level of reliability in measurement of the dimensions of adaptability and cohesion in families.

Internal consistency reliability for each subscale and the total scale using Cronbach's alpha was calculated employing the split half method on a sample of 2,412 respondents. Total scale alpha was .90 for both the subgroups and the total sample (Olson \& Tiesel, 1991). The total scale FACESII alpha for this sample was .93. Subscale alpha's were .84 for adaptability and .90 for cohesion in this sample. All scores are well above the recommended .70 (Nunnally, 1978).

Scoring for cohesion was completed by first summing the positive item scores and then summing the negative item scores. After the sums were obtained, the sum of the positive items was subtracted from the constant of 36 and added to the sum of the negative items. This procedure was repeated for adaptability, changing the constant to 12 . Scores for family balance were calculated using the linear scoring and interpretation sheet provided by the authors to 
identify a family balance score. The higher the score the more balanced the family (Olson \& Tiesel, 1991).

The Postpartum Adaptation Scale (PAS). This tool was developed to record women's feelings and responses following childbirth (see Appendix F). The tool was chosen for this study because of the ability to comprehensively measure post birth maternal adaptation from both a physical and psychosocial standpoint. The instrument consists of 96 items that are statements about a woman's feelings following childbirth and took 15 to 20 minutes to complete. The items were scored on a likert-type scale resulting in ordinal level data with higher scores indicating lower adaptive levels. The tool contains five subscales. They are physical, psychological, social role, mother-infant relationship, and infant caretaking.

Content validity was established by a panel of five experts. No CVI was calculated by the tool author. Construct validity was supported using the experimental methods approach (Waltz, Strickland \& Lenz, 1986). The tool was tested using a non-probability sample of 194 childbearing women whose infants were between 1 and 12 weeks of age (Nichols, 1988). Total scale alpha ccefficient was .94. Subscale alpha's were physical $=.79$, psychological $=.89$, social role $=.75$, mother-infant relationship $=.87$, and infant caretaking $=.84$. In the current study the total scale coefficient alpha for the PAS was .94. Subscale 
alpha's were physical $=.76$, psychological $=.90$, social role $=.81$, mother-infant relationship $=.72$, and infant-caretaking =.73. Sample reliability coefficients on all subscales were above the acceptable .70 as suggested by Nunnally (1978). Table 1 summarizes the sample reliabilities for each instrument.

Table 1

Instrument Reliability

\begin{tabular}{llc}
\hline \multicolumn{1}{c}{ Variable } & Instrument & alpha \\
\hline Family Support & PRQ85 & .91 \\
Family Stress & FIIE & .83 \\
Family Balance & FACESII & .93 \\
Maternal Adaptation & PAS & .94 \\
\hline
\end{tabular}

\section{Data Collection Process}

Following approval from the University of San Diego Committee on Protection of Human subjects and corresponding committees in each of the participating agencies (see Appendix H), subjects were recruited from childbirth education classes in the northwestern United States. Permission for the researcher to attend the classes was obtained from the educator teaching the class. The study was first explained to the childbirth education class as a 
group and then volunteers for study participation were requested. Those interested in participating were given consent forms to read and sign. Consent was obtained from each pregnant woman (see Appendix I) and each significant other (see Appendix J).

After the consent was signed, each participating subject was given a copy of the consent and the name, address, and phone number of the researcher and research assistant. They were also given a booklet of questionnaires to complete at a break in the childbirth class and return to the researcher. The questionnaire booklets were color coded pink for the mother and blue for the significant other for clarity of identification during data analysis. Each questionnaire booklet contained a code number for participant identification and tracking. The pregnant women and their significant others were assigned the same code number and these numbers remained the same on the post birth questionnaires. The booklets consisted of a prenatal demographic form, the FILE, the PRQ85 Part 2, and the FACESII. Identification information (see Appendix $\mathrm{K}$ ) provided by the participants was kept with the consent signature sheets by the researcher in a secure location separate from the rest of the data. The information sheets were destroyed after summaries of the study results were mailed to those families who requested them. 
A postcard addressed to the researcher was given to each pregnant woman containing her code number and a place to record the birth date of her infant. The woman was asked to return this postcard to the investigator within 5 days after delivery. Hospital delivery records and local newspapers were also consulted to obtain delivery dates. When delivery notification was received, each family was sent a card to congratulate them on the birth of the baby. Approximately six weeks after the birth, participating subjects were mailed a second packet of the instruments. This packet consisted of a letter of explanation (see Appendix L), a post birth booklet for the mother, and a post birth booklet for the significant other. The post birth significant other booklet contained: A demographic form, the FILE, the PRQ85, and the FACESII. The mother's booklet contained: A demographic form, the PAS, the FILE, the PRQ85 Part 2, and the FACESII. The subjects were asked to complete the instruments and return them to the investigator by mail in an enclosed self-addressed and stamped envelope. Subjects received a phone call as a reminder ten days after the packet was mailed if the return data were not received by the researcher. When the second packet was received by the researcher a small gift was mailed to the family.

\section{Data Analysis}

Data analysis was accomplished using the statistical Packages for the Social Sciences computer software package 
(SPSS, 1993). Data were reduced by obtaining individual scores for the FILE, the PRQ85 Part 2, FACESII, and PAS. Correlations were calculated between the scores of each mother and her significant other. Copeland and White (1991) suggested that while there is no ideal method of obtaining a unit family score, if the individual scores are highly correlated a mean score is appropriate. Family scores were then calculated on each measure completed by both the childbearing woman and her significant other by using the mean as a group level unit of analysis.

Multiple regression and stepwise multiple regression techniques were then employed using the family mean score to determine the effect of the predictor variables on maternal adaptation. Each prenatal and post birth variable was regressed on post birth maternal adaptation in separate analysis. Then a stepwise regression was employed to determine which of the predictor variables most influenced the value of the $\underline{\mathrm{R}}^{2}$ statistic (Schroeder, sjoquist, \& Stephen, 1986). The relationships of demographics to the study variables were described in a post hoc analysis using correlational and stepwise multiple regression techniques.

\section{Summary}

In this chapter the design of the study was discussed. A detailed discussion of the sampling design and instrumentation was then presented. Finally the procedures used for collecting and analyzing the data were outlined. 
CHAPTER 4

RESULTS

Results of analysis and interpretation of the study data are presented in this chapter. Descriptive data relative to the study variables are reported followed by a discussion of hypotheses testing. Finally, the results of the post hoc analysis of the demographics are presented.

\section{Descriptive Data Analysis}

Prenatal and post birth scores on each scale were calculated for childbearing women and their significant other. Maternal adaptation scores were calculated only post birth. The sample mean score for maternal adaptation was 161.79 from a possible high score of 363 . The lower scores indicate a greater level of adaptation. Sample scores ranged from 110 to 234 with a standard deviation of 25.59 . Family unit scores for each family variable, both prenatal and post birth, were calculated as follows. The scores for each independent variable of each childbearing woman and her significant other were correlated. The scores of the childbearing woman and her significant other for each of the three measures were determined to be significantly correlated both prenatal and post birth. Therefore, a mean score for the family dyad was calculated. These family dyad 
mean scores were used for the analysis (Copeland and White, 1991). The $\underline{t}$ test results indicated a significant difference in dyad mean scores for the prenatal PRQ85 and the post birth FILE. On tables 2 and 3 mother/significant other correlation's and $t$ - tests are displayed. Table 2

Correlation's Between Independent Variable at Prenatal and Post Birth Measurements

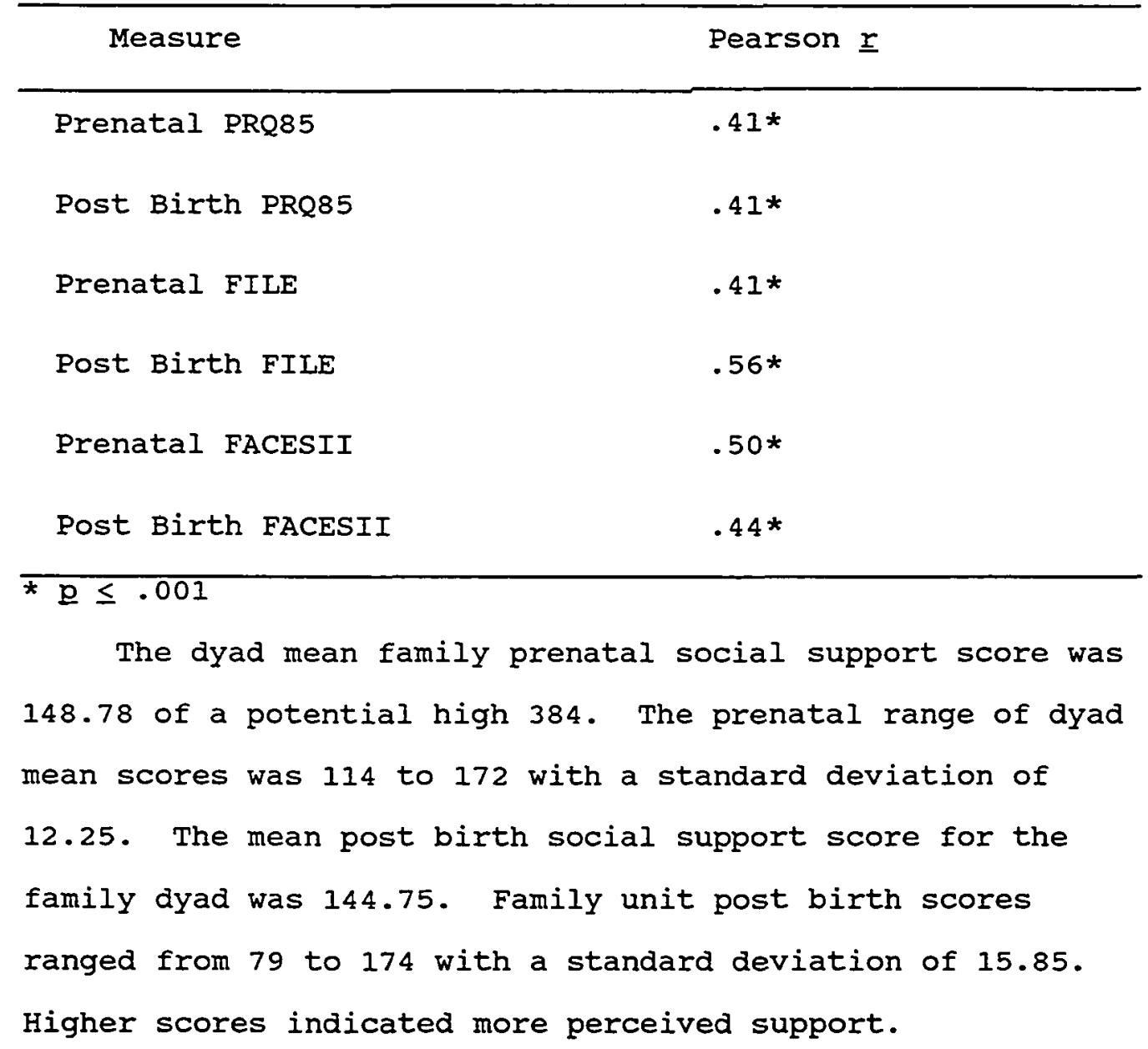


The data for family stress were analyzed using weighted scores. The family dyad sample mean score for prenatal family stress was 427.21 of a possible 3307 and the standard deviation for this variable was 229.14. Prenatal dyad family stress scores ranged from 41.50 to 1196. Post birth dyad family stress scores ranged from 71.50 to 1246 . The Table 3

$t$ - Test for the Independent Variables at Prenatal and Post Birth Measurement

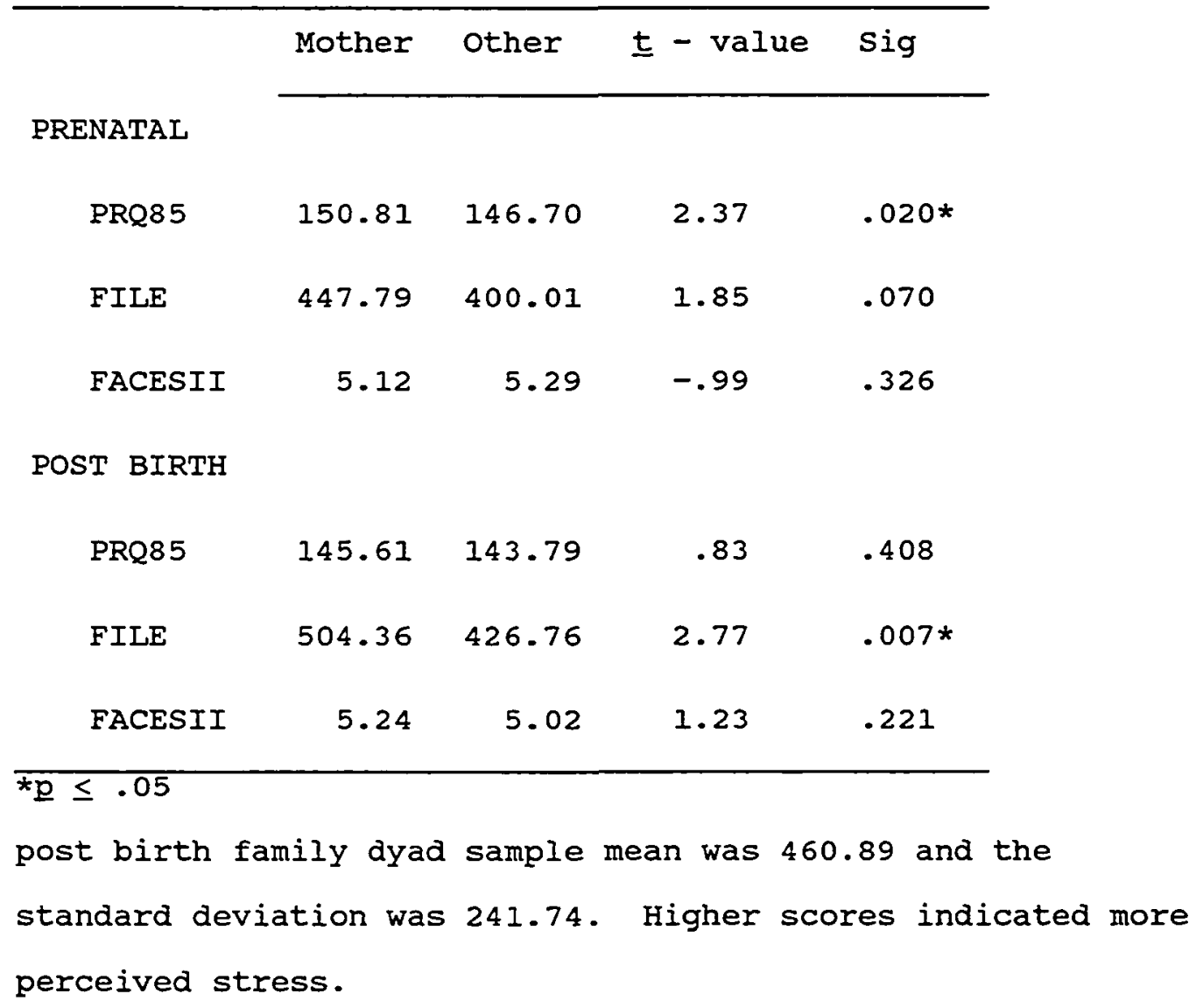


The data for family balance was analyzed using the numerical value for family type. The dyad mean prenatally was 5.18 out of a possible high of 8 and the standard deviation was 1.23. Dyad mean scores ranged from 1.75 to 7.25. The post birth sample mean was 5.11 and the standard deviation was 1.40 . Scores ranged from 1.50 to $7.75 ;$ higher scores indicated more balanced families. The mean family scores were lower for social support and higher for stress in the post birth period. Families in this sample scored approximately the same for family balance in both measurements. The prenatal mean scores and standard deviations along with the potential and actual range of all scale scores are displayed on Table 4. Post birth mean scores and standard deviations with the potential and actual range of all scale scores are displayed on Table 5.

\section{Hypothesis Testing}

The Pearson product-moment correlation coefficient (Pearson $\underline{\text { ) }, ~ M u l t i p l e ~ R e g r e s s i o n, ~ a n d ~ t h e ~ s t e p w i s e ~ M u l t i p l e ~}$ Regression Programs of the Statistical Package for the Social sciences were employed to test the study hypotheses. only dyad scores were used in this analysis. Hypothesis 1

Prenatal family social support has a positive effect on post birth maternal adaptation.

A Pearson $I$ correlation coefficient was used to examine the strength of the relationship between prenatal family 
Table 4

Prenatal Individual and Dyad Mean Scores, Ranges, and

Standard Deviations for PRQ85, FILE, FACESII

\begin{tabular}{|c|c|c|c|c|c|c|}
\hline Variable & $\begin{array}{l}\text { Pot } \\
\text { Rar }\end{array}$ & $\begin{array}{l}\text { Lential } \\
\text { ige }\end{array}$ & & $\begin{array}{l}\text { Actual } \\
\text { Range }\end{array}$ & Mean & $\underline{\mathrm{SD}}$ \\
\hline \multicolumn{7}{|l|}{ Mother ${ }^{a}$} \\
\hline PRQ8 5 & 25 & -175 & 98 & -175 & 148.83 & 16.37 \\
\hline FILE & 0 & -3307 & 0 & -1457 & 454.00 & 277.33 \\
\hline FACESII & 1 & -8 & 1 & -8 & 5.5 & 1.51 \\
\hline \multicolumn{7}{|l|}{ other ${ }^{b}$} \\
\hline PRQ85 & 25 & $-\quad 175$ & 105 & -175 & 146.24 & 15.94 \\
\hline FILE & 0 & -3307 & 0 & -1259 & 407.79 & 254.93 \\
\hline FACESII & 1 & -8 & 1.5 & -8 & 5.45 & 1.70 \\
\hline \multicolumn{7}{|l|}{ Dyade } \\
\hline PRQ85 & 25 & -175 & 114 & -172 & 148.78 & 12.25 \\
\hline FILE & 0 & -3307 & 41.5 & -1196 & 427.21 & 229.14 \\
\hline FACESII & 1 & -8 & 1.75 & -7.25 & 5.18 & 1.23 \\
\hline $\begin{array}{l}a=\underline{n}=87 \\
b=\underline{n}=87 \\
c=\underline{n}=87\end{array}$ & & & & & & \\
\hline
\end{tabular}


Table 5

Post Birth Individual and Dyad Mean Scores, Ranges, and

Standard Deviations for PAS, PRO85, FILE, FACESII

\begin{tabular}{|c|c|c|c|c|c|c|}
\hline Variable & \multicolumn{2}{|c|}{ Potential } & & Actual & Means & $\underline{\mathrm{SD}}$ \\
\hline \multicolumn{7}{|l|}{ Mother ${ }^{a}$} \\
\hline PAS & 96 & -363 & 110 & -234 & 161.78 & 25.59 \\
\hline PRQ85 & 25 & -175 & 71 & -175 & 145.53 & 19.29 \\
\hline FILE & 0 & -3307 & 50 & -1402 & 504.36 & 289.78 \\
\hline FACESII & 1 & -8 & 1 & -8 & 5.51 & 1.49 \\
\hline \multicolumn{7}{|l|}{ otherb } \\
\hline PRQ85 & 25 & -175 & 87 & -173 & 143.79 & 17.8 \\
\hline FILE & 0 & -3307 & 40 & -1405 & 426.76 & 254.68 \\
\hline FACESII & 1 & -8 & 1.5 & -8 & 5.43 & 1.7 \\
\hline \multicolumn{7}{|l|}{ Dyad } \\
\hline PRQ85 & 25 & -175 & 79 & -174 & 144.75 & 15.85 \\
\hline FILE & 0 & -3307 & 71.5 & -1245 & 460.89 & 241.74 \\
\hline FACESII & 1 & -8 & 1.5 & -7.75 & 5.11 & 1.40 \\
\hline
\end{tabular}

Reproduced with permission of the copyright owner. Further reproduction prohibited without permission. 
social support and post birth maternal adaptation. The correlation between prenatal family social support and post birth maternal adaptation was $\underline{\underline{r}}=-.340, \underline{\mathrm{p}}<.002$. A negative correlation in this instance indicated a positive relationship as the low scores for maternal adaptation equal higher adaptive levels and the high scores for social support indicate more perceived support. Hypothesis 1 was supported.

Hypothesis 2

Prenatal family stress has a negative effect on post birth maternal adaptation.

A Pearson $r$ correlation coefficient was used to examine the strength of the relationship between prenatal family stress and post birth maternal adaptation. The correlation between prenatal family stress and post birth maternal adaptation was $\underline{r}=.27, \underline{p}<.01$. A positive score in this instance indicated a negative relationship; low scores for maternal adaptation equal higher adaptive levels, and the high scores for family stress indicate more perceived stress. Hypothesis 2 was supported. Hypothesis 3

Prenatal family balance has a positive effect on post birth maternal adaptation.

The correlation between prenatal family balance and post birth maternal adaptation where $\underline{r}=-.16, \underline{p}<.20$ was not statistically significant. Hypothesis 3 was not 
supported. Table 6 is a correlation matrix of the prenatal independent variables and post birth maternal adaptation. Hypothesis 4

Post birth family social support has a positive effect on post birth maternal adaptation.

The correlation between post birth family social support and post birth maternal adaptation was $\underline{r}=-.70$, $\underline{p}<.001$. As identified in the prenatal measurement, a negative correlation in this instance indicates a positive relationship as the low scores for maternal adaptation equal higher adaptive levels and the high scores for social Table 6

Correlation Matrix of the Prenatal Independent Variables and Post Birth Maternal Adaptation

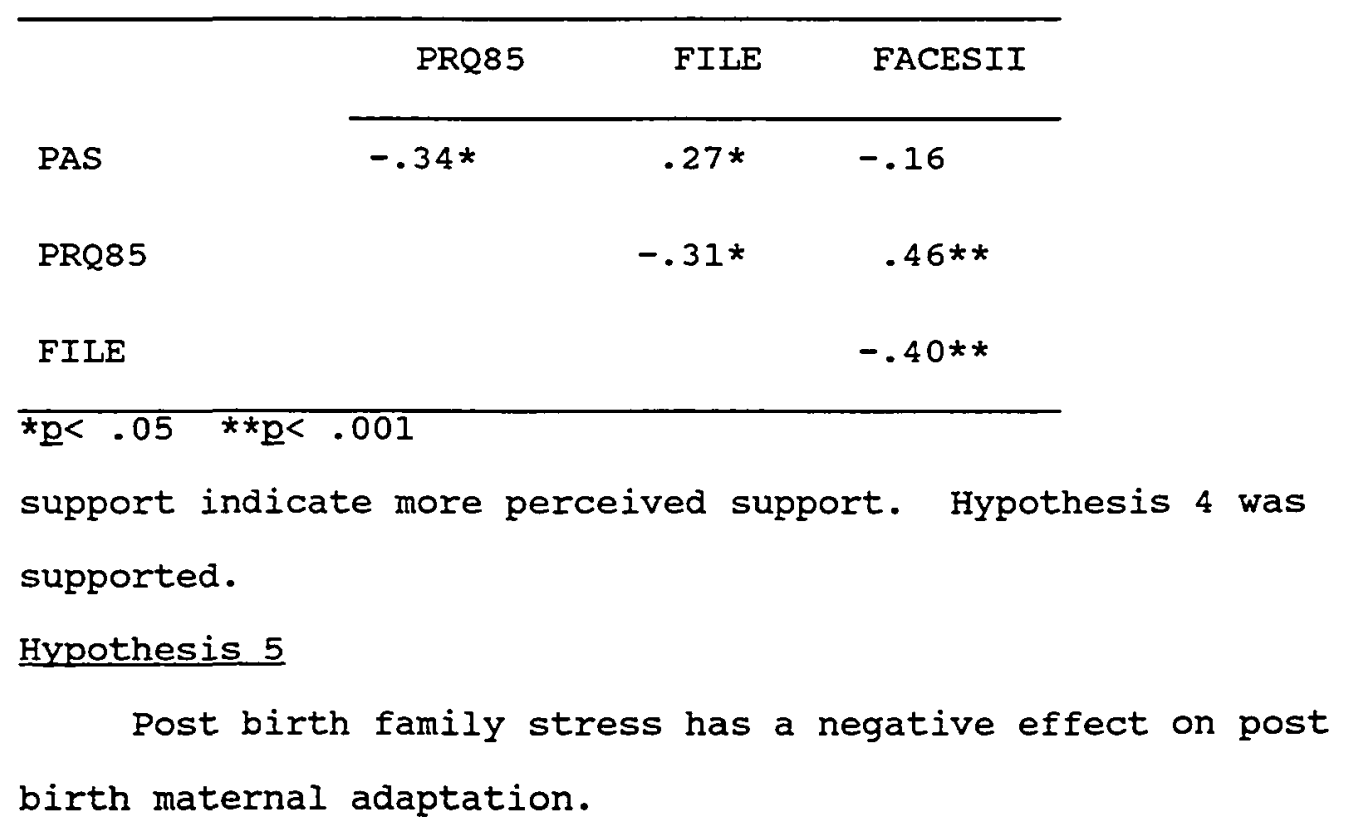


The correlation between post birth family stress and post birth maternal adaptation was $\underline{r}=.45$, 마 .001 . As in hypothesis 2 , a positive score indicates a negative relationship. The low scores for maternal adaptation are indicative of higher adaptive levels and the high scores for family stress indicate more perceived stress. Hypothesis 5 was supported.

Hypothesis 6

Post birth family balance has a positive effect on post birth maternal adaptation.

The correlation between post birth family balance and post birth maternal adaptation where $\underline{x}=-.3756, \underline{p}<.001$ was statistically significant. The same variables were not significantly correlated in the prenatal period. Table 7 is a correlation matrix of the post birth independent variables and post birth maternal adaptation. Hypothesis 6 was supported.

Table 7

Correlation Matrix for the Post Birth Independent Variables and Post Birth Maternal Adaptation

\begin{tabular}{lccc}
\hline & \multicolumn{1}{c}{ PRQ85 } & FILE & FACESII \\
\cline { 2 - 4 } PAS & $-.43 * *$ & $.45 * *$ & $-.38 * *$ \\
PRQ85 & & $-.32 *$ & $.70 * *$ \\
FILE & & $-.70 * *$ \\
\hline
\end{tabular}


Hypothesis 7

Post birth family social support, family stress, and family balance effect post birth maternal adaptation more than each individual family variable or the same combined variables in the prenatal period. This hypothesis was tested using a multiple regression in order to determine the predictive value of all the independent variables at each measurement. A stepwise multiple regression was used to determine the combination of variables with the best predictive power. Therefore, the contribution of each independent variable to explain post birth maternal adaptation was examined.

Multiple regressions were run for only the prenatal measurement and then only the post birth measurement. Finally a stepwise multiple regression was done with all predictor variables in the equation. The minimal level of significance for the stepwise $\underline{F}$ test, as well as, the significant $t$ was 0.05 as predetermined using cohen's power analysis technique.

Maternal adaptation was regressed on the prenatal variables family social support (PRQ85), family stress (FILE), and family balance (FACESII). Family social support and family stress explained $18 \%$ of the variance in post birth maternal adaptation. Fámily balance was not significant in this equation. 
When maternal adaptation was regressed on post birth family social support, family stress, and family balance again, only stress and support were significant explaining $33 \%$ of the variance in post birth maternal adaptation. Family balance was not statistically significant. Figure 2 illustrates the beta's, significance level and $\underline{R}^{2}$ for both prenatal and post birth predictor variables.

Using stepwise regression in which maternal adaptation was regressed on all the family variables, only two of the six independent variables; post birth family stress and post birth family social support were predictive of post birth maternal adaptation. These two variables explained approximately $33 \%$ of the variance (see Table 8). Hypothesis 7 was only partially supported.

\section{Additional Data Analyses}

Two additional regression analyses were completed that warrant reporting. First, multiple regression analysis was done using the demographics as the independent variables. The only significant predictors of maternal adaptation among the demographic variables were number of other children in the household $(\underline{t}=.027)$ and the family income category $(\underline{t}=$ $.023)$. When the family variables and the demographics were put into a stepwise multiple regression, only post birth family social support and post birth family stress were predictive of post birth maternal adaptation. In this analysis $\underline{R^{2}}=.33 ; \underline{F}=19.34$. 
Figure 2. Regression of Prenatal and Postbirth Family Social Support,

Family Stress, and Family Balance on Post Birth Maternal Adaptation

Prenatal Post Birth

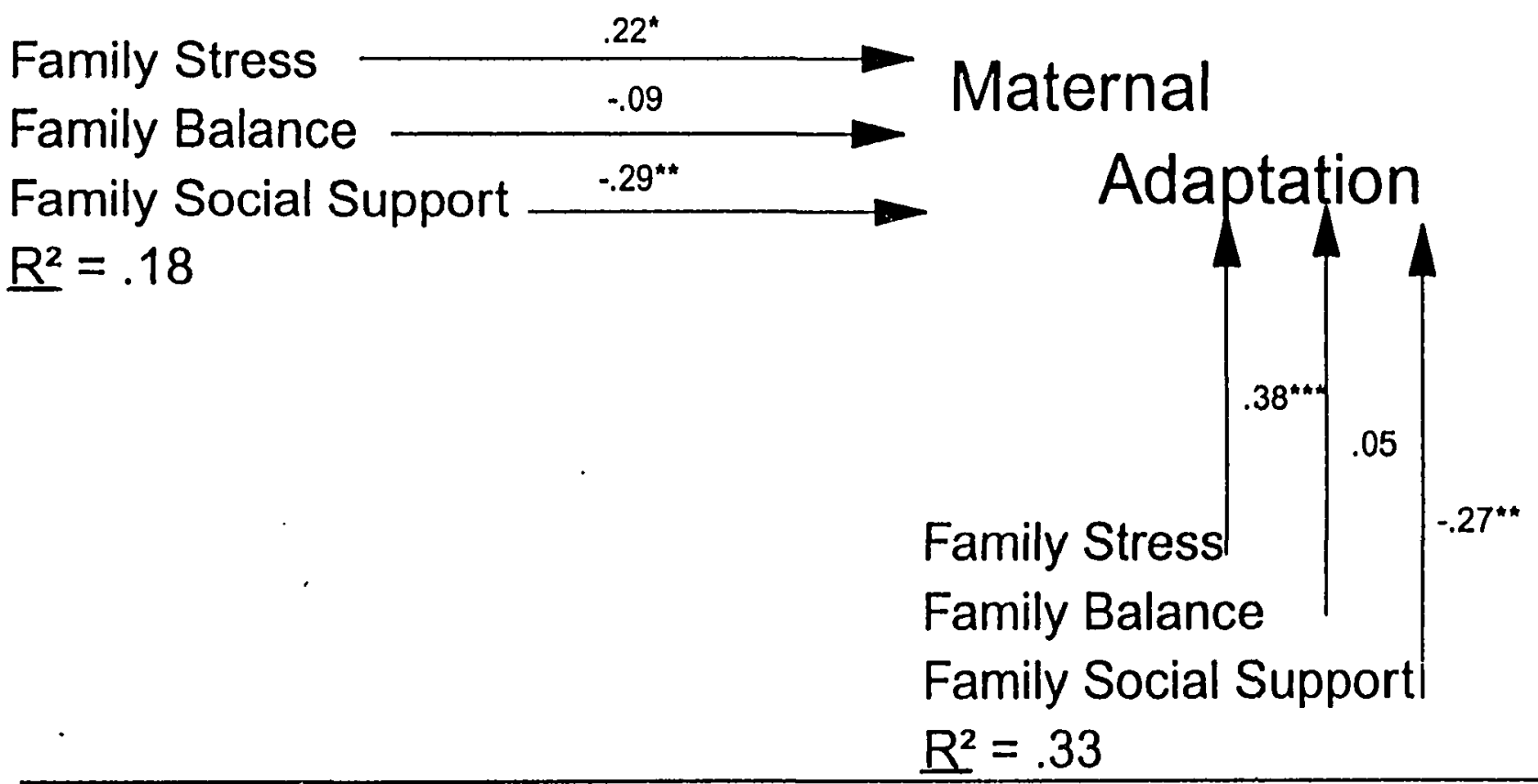

${ }^{\star} \mathrm{g}<.05,{ }^{* \star} \mathrm{Q}<.01,{ }^{\star * \star} \mathrm{D}<.001$ 
Table 8

Stepwise Regression: Relationship of Post Birth Maternal

Adaptation to Post Birth Family stress (FILE) and Post Birth

Family Social Support PRO85

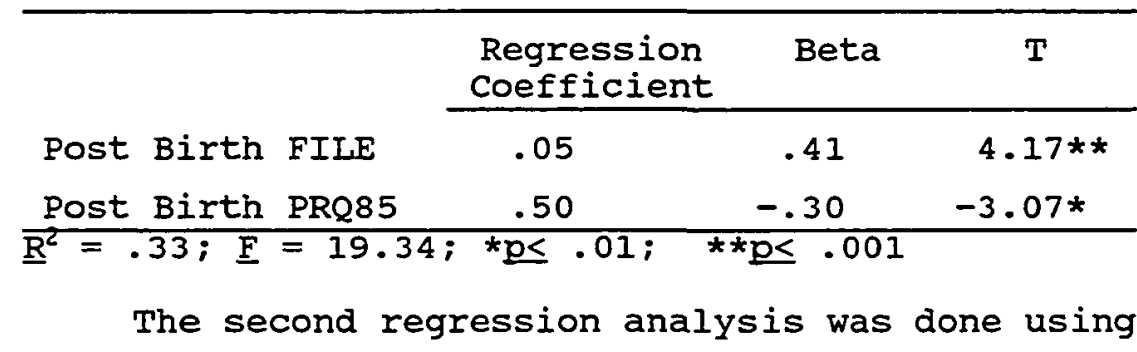

individual scores at the prenatal and post birth

measurements. For mothers, regression analysis of family

variables prenatally predicting PAS scores were significant where $\underline{R^{2}}=.20, \underline{F}=9.28, \underline{p}<=.001$. Significant other regression analysis of prenatal family variables was not significant in predicting PAS scores. When the individual scores were used as predictors post birth, both mother individual scores $\left(\underline{R}^{2}=.49, \underline{F}=25.8, \underline{p<}=.001\right)$ and significant other individual scores $\left(\underline{R}^{2}=.13, \underline{F}=4.89\right.$, $\underline{p} \leq=.01$ ) on the family variables were statistically significant in predicting post birth maternal adaptation.

\section{Summary}

Analysis and interpretation of the data were presented in this chapter. Hypothesis $1,2,4,5,6$ were supported. Hypothesis 3 was not supported and hypothesis 7 was partially supported. Post birth family balance was significantly correlated to post birth maternal adaptation. 
When post birth family balance was entered into the regression equation with pre and post birth family stress and social support, only post birth family stress and post birth family social support were significant. 


\section{CHAPTER 5}

\section{DISCUSSION}

The study findings are discussed in this chapter along with the significance of those findings in relation to previous work. Strengths and Iimitations of the study are identified, as well as implications of the study for future research. Finally, the usefulness of the study findings for the development of nursing theory, nursing practice, and nursing education are explored.

\section{Discussion of Study Findings}

Findings of this study indicated that family stress and family support in the perinatal period have a significant effect on post birth maternal adaptation. These findings are congruent with other studies in the literature. Affonso and Mayberry (1990) found that relationship and financial stressors were important concerns to women post birth. Mercer \& Ferketich (1988) noted that antepartum stress increased depression during pregnancy. The Resiliency Model of Family Stress (McCubbin, 1993) depicts resources that families develop to manage stressful transitions such as childbirth. These rescurces can be within the individual, family system, or community. Qne of these resources that has demonstrated a positive effect on families and their 
individual members in coping with stress is social support (Danielson, Hamel-Bissell \& Winstead-Fry, 1993). Social support is also identified in the literature as a key variable in maternal adaptation (Turner \& Avison, 1985; Dormire, Strauss and Clarke, 1989) and as an important factor in reducing the stress of having a handicapped infant (Capuzzi, 1989).

In the current study the correlations are more significant post birth than prenatally. The strongest correlation noted was between post birth family support and post birth maternal adaptation $(\underline{r}=.69)$. The next most powerful correlation $(\underline{r}=.45)$ was between post birth family stress and post birth maternal adaptation. The findings indicated that perceived family stress and family social support during the post birth period significantly affected adaptive levels of the sample new mothers. Similar phenomena were found in the literature. For example, stress and support in families were identified by Pittman and Lloyd (1988) as factors that produce significant independent effects on the individual family member's perceptions of the quality of family life. Affonso (1987) found that stress and depression were correlated in postpartum women and Flagler (1990) noted that support, spousal relationships, and physical problems were all significantly correlated to maternal adaptation four to six weeks post birth. 
Family balance was not found to be significantly correlated with post birth maternal adaptation either in the prenatal or post birth period. However, strong correlations were noted between family balance and family stress, as well as family balance and family social support. It is probable that family social support had a mediating effect on family stress in this study. Therefore, the total effect of family balance on post birth maternal adaptation was reduced. According to Stress Theory, family resources such as family social support act as intervening factors between stress and adaptational outcomes. Family resources may act as stressbuffering variables and reduce the effect of stress on family well-being (Lavee, Mccubbin, \& Olson, 1987). When the model for this study was tested, post birth maternal adaptation was regressed on prenatal family social support, prenatal family stress, prenatal family balance, post birth family social support, post birth family stress, and post birth family balance. Family stress and family social support post birth explained approximately $33 \%$ of the variance in post birth maternal adaptative levels. All of the prenatal variables and post birth family balance were not significant in this equation.

The data were also analyzed regressing maternal adaptation on family social support, family stress, and family balance only prenatally. In this analysis, prenatal family stress and social support were statistically 
significant but explained only $18 \%$ of the variance in post birth maternal adaptation. When maternal adaptation was regressed on post birth family social support, family stress, and family balance; post birth family stress and family social support explained $33 \%$ of the variance. The analysis of the study hypotheses indicated that while family support and family stress before birth may have some influence on the new mothers post birth adaptive level, these factors were much more significant after the baby was born.

The role of demographics was also analyzed. Only two of the study demographics; number of other children and family income were significantly correlated to post birth maternal adaptation. All demographics were added to the regression equation with all study variables and still only family social support and family stress post birth were shown to significantly affect post birth maternal adaptation. Thus, post birth family social support and post birth family stress predicted the new mother's adaptive level as well alone as when the demographics were added. Another analysis examined the effect of the individual perceptions of family social support, family stress, and family balance on the new mother's post birth adaptive levels. In this analysis the best predictors of a new mother's post birth adaptation were that woman's own perceptions of her family's support and stress. The most 
significant predictors were post birth with family stress and family social support explaining $49 \%$ of the variance in post birth maternal adaptation.

The findings of this study indicated that stress and support in the family had a significant effect on post birth maternal adaptive levels. In the study sample, as family support increased and family stress decreased, post birth maternal adaptive levels increased. The effect of these factors on a new mother's adaptation was much more significant in the post birth period. other family research has also found that stress and support within the family unit are very important factors influencing adaptive outcomes (McCubbin, 1993).

\section{Strengths and Limitations}

This study started with a sound research question validated in the literature and central to nursing practice. The study was further strengthened by the consistency of the design with the methods employed. The sample size met the power criteria, and the sample was solicited from two states and five diverse locations. The majority of the sample were from a rural environment in Montana and the demographics of the sample were very typical of Montana families.

The study was designed as a predictive correlational study to describe the effects of perinatal family stress, family social support, and family balance on a new mother's adaptation to the birth of her infant. Methods involved 
selecting a sample from a childbearing population and utilizing measurement tools that had demonstrated validity and reliability in quantifying the predictor variables. The tools also demonstrated adequate validity and reliability in this study. The regression analysis used fit the design and methods of the study and resulted in significant findings that can be applied to nursing practice. The criteria used to determine the sample size for this study are outlined by Cohen (1987). The study sample of 87 families was sufficient to establish a power of .995 at the .05 significance level.

The study limitations include method of sampling, resources used for subject solicitation, and problems with the instruments that threaten the internal validity. Since this was a sample of convenience, not a random sample, the findings of the study are not generalizable to the population. The sample was mostly Caucasian, middle class, and married. The families were $76 \%$ first time parents. This probably was a result of limiting subject solicitation to childbirth preparation classes. These classes have been identified to meet the needs of primarily traditional middle class families. In some cases a fee was charged for the class which would have limited those of lower socioeconomic means. Many of the classes were offered as a service provided by a private MD's office or a hospital. In these cases there was no fee but all participants were receiving 
prenatal care. The sample selected was not representative of varied cultures or family forms.

The use of mean scores to define the family as a unit of analysis was also a limitation. Although this is an accepted procedure with highly correlated individual scores such as resulted in this study, valuable data may be lost when individual scores are not compared and analyzed. Loveland-Cherry, Horan, Burman, Youngblut, and Rodgers (1993) identified four ways to score family data that measures structural properties of the family such as support, stress, and balance. These are: a) use each members discrete score, b) sum the individual scores and use a family mean, c) use a discrepancy or difference score, and d) use weighted scores. The second method was used in this study. Loveland-Cherry et al. (1993) noted that the assumption here is that each individual's score is equally important and instrumental in creating the family experience. The problem with this method of scoring family data is that two families may have the same mean score yet the individual scores are quite different.

Another Iimitation of this study was an internal validity problem regarding the instruments chosen for measurement of the family data. The FACESII was designed to measure an individual's perception of the family. The FILE was also completed by each individual and used in this study as a measure of the individual's perception of family 
stress. The PRQ85 measures an individual's perception of social support for that individual and not the family as a unit. The use of social support as a family variable could be strengthened by either modification of the PRQ85 or development of a new tool to measure the individual's perception of family support.

The reliabilities on 6 of the 9 subscales of the FILE were low. While the authors of this instrument noted that this would occur, one must question the ability of the tool to reliably measure these concepts. However, the FIIE had an acceptable total scale reliability, which raises a question about the existence of subscales.

Implications for Future Research and Nursing Theory Development

Family-child nursing has a unique opportunity to assist growing families in the adjustment, adaptation, and integration process from conception through childhood. Styles (1990) noted that the breadth and scope of familychild nursing "revolves indivisibly around the holistic concept of the origins of the family and the very roots of society" (p. 347). It is therefore essential to nursing and to society that nurse scientists define variables and develop theory to guide interventions that will positively influence the post birth family. In this study, family variables that impact a new mother's adaptive levels were 
examined. The limitations and findings of the study identified several areas for future research.

How can family variables be more precisely measured? Would applying different scoring techniques result in more significant findings? The arena of family research is a frontier for development. There are many gaps in the literature and questions yet to be answered regarding family measurement and analysis of family data. There are few if any precise measurement tools for the family as a unit. Techniques for scoring and analyzing family data leave much to be desired. Further research is needed to develop better tools, scoring, and analysis procedures.

would the results of the study be very different if the sample were more culturally diverse? There is a large Native American population in the geographic area where the study was conducted. Would the results be different in this population? If this population had been represented in this sample would that have affected the results? What adaptation in methods would be necessary to study Native American populations adequately, accurately, and with cultural sensitivity?

How does the rural environment of the sample effect the results? Is there a difference between rural and urban families? While Montana is a rural state there are population centers within the state. The majority of this sample were from these population centers. Would the urban 
subjects look different from the rural subjects if these data were to be analyzed and rural included as one of the study variables?

What post birth family nursing interventions might help families obtain the support needed to decrease family stress and increase both maternal and family adaptive levels? In this study, as in others, social support was identified as important in buffering stress and increasing adaptive levels. The results of this study indicated that these factors were especially important post birth.

Significance of the study for Nursing Practice and Education.

Mothers remain the ones primarily responsible for nurturing and providing care to infants and young children. The mother is the central figure in childbearing families. It is therefore important to identify how the adaptation of the childbearing woman relates to the family as a unit. This information can help guide the development of specific nursing interventions, both in acute care settings and beyond, that enhance maternal adaptation and family responses during the transitional period following birth.

The results of this study also indicated that family social support and family stress in the first six to eight weeks following birth significantly affect maternal adaptive levels. Yet, most of the health care provided for childbearing families is provided in the prenatal period. 
The results of this study indicated that nurses need to become more involved with families post birth. Currently, most women are discharged from the hospital or birth center within 24 hours post delivery. This leads to new mothers being isolated if they don't have a good support network in place. Current practice offers little support from the health care system for the mother. She is usually not seen by her primary provider or any other health professional until six weeks post delivery. More emphasis in nursing practice and education should be placed on home care for families during this critical post birth period. McCubbin (1993) identified a distinct role for nurses working with families during times of transitional crisis and change such as childbearing. This role includes supporting and enhancing the families' strengths, assisting the family in maintaining linkages with community supports, and aiding the family in the appraisal of what is a realistic fit for them in their particular situation. Through these efforts, nurses can assist families in the process of adaptation. Empirical evidence that family support enhances mothering can also be used to influence health policy. Health policy based on these data will help to initiate policy that favors support of post birth families. Such potential policies include parental leave, making health care support services available to all young families, and financing new programs within the existing 
health care system to better serve the post birth childbearing family.

\section{Summary}

It was found in this study that family stress and family support significantly affect a new mother's ability to adapt to the birth of her infant. The study findings also suggest that family stress and support after the birth of a new infant are particularly significant, yet most interventions are structured for the prenatal period. Using existing theory and further development of studies relating to how the family and new mother are enmeshed may help nurses establish the distinct role defined by Mccubbin (1993) for family-child nursing. 


\section{REFERENCES}

Affonso, D.D. (1987). Assessment of maternal postpartum adaptation. Public Health Nursing, 4 , 9-20.

Affonso, D.D. \& Mayberry, L.J. (1990). Common stressors reported by a group of childbearing American women. Health Care for Women International, 11, 331-345. Barnard, K.E., Snyder, C., \& Spietz, A. (1991). Supportive measures for high-risk infants and families. In A.I. Whall \& J. Fawcett (Ed.), Family theory development in nursing: state of the science and art. (pp. 139-176). Philadelphia: Davis.

Brandt, P., \& Weinert, C. (1981). The PRQ: A social support measure. Nursing Research, 30, 277-280.

Brown, M.A. (1987). How fathers and mothers perceive prenatal social support. The American Journal of Maternal Child Nursing, 12, 414-418. Buckwalter, K.C. \& Maas, M. I. (1989). True experimental designs. In P.J. Brink \& M.J. Wood (Ed.). Advanced Design in Nursing Research (pp. 27-55). Newbury Park: Sage.

Carter, E.A \& McGoldrick, M.(Eds.). (1980) The family life cycle: A framework for family therapy. New York: Gardner. 
Capuzzi, C. (1989). Maternal attachment to handicapped infants and the relationship to social support. Research in Nursing and Health, 12, 161-167.

Cohen, J. (1987). Statistical power analysis for the behavioral sciences. (rev. ed.) Hillsdale NJ: Lawerence Erlbaum Associates.

Combrink-Graham, L. (1985). A developmental model for family systems. Family process, 24(2), 139-150.

Copeland, A., \& White, K. (1991). Studying families. Newbury Park: Sage.

Crockenberg, S., \& Mccluskey, K. (1986). Changes in maternal behavior during the baby's first year of life. Child Development, $\underline{3}, 746-453$.

Curry, M.A. (1983). Variables related to adaptation to motherhood in "normal" primiparous women. Journal of Obstetric Gynecologic, and Neonatal Nursing, 12, 115-120. Danielson, C.B., Hamel-Bissell, B. \& Winstead-Fry, P. (1993). Families, health, and illness: Perspectives on Coping and intervention. St. Louis: Mosby. Dormire, S.L., Strauss, S.S., \& Clarke, B.A. (1988). Social support and adaptation to the parent role in first-time adolescent mothers. Journal of obstetric Gynecologic, and Neonatal Nursing, 18(4), 327-337. Duvall, E.M. \& Miller, B.C. (1985). Marriage and family development. (6th ed.). New York: Harper and Row. 
Flagler, S. (1990). Relationships between stated feelings and measures of maternal adjustment. Journal of obstetric Gynecologic, and Neonatal Nursing, $19(5), 411-416$.

Gruis, M. (1977). Beyond maternity: Postpartum concerns of mothers. The American Journal of Maternal Child Nursing, $\underline{3}, 182-188$.

Hill, R. (1949). Families under stress. New York: Harper \& Row.

Hill, R. \& Mederer, H. (1983). Critical transitions over the family life span: Theory and research. In H.I. Mccubbin, M.B. Sussman \& J.M., Patterson (Ed.), Social stress and the family (pp. 39-59). New York: Haworth. Humenick, S.S., \& Bugen, I.A. (1987). Parenting Roles: Expectations versus reality. The American Journal of Maternal Child Nursing, 12, 36-39.

Kaufman, K.J., \& Hall, L.A. (1989). Influences of the social network on choice and duration of breast-feeding in mothers of preterm infants. Research in Nursing and Health, 12, 149-159.

Krathwohl, D.R. (1985). Social and behavioral science research. San Francisco: Jossey-Bass. Laizner, A.M. \& Jeans, M.E. (1990). Identification of predictor variables of a postpartum emotional reaction. Health Care for Women International, 11, 191-207. Lavee, Y., McCubbin H.I. \& Olson D.H. (1987). The effect of stressful life events and transitions on family 
functioning and well-being. Journal of Marriage and the Family. 49, 857-873.

Lewis, J.M. (1989). The birth of the family: An empirical inquiry. New York: Brunner/Mazel.

Loveland-Cherry, C.J., Horan, M., Burman, M., Youngblut, J.,

\& Rodgers, W. (1993). Scoring family data: An

application with preterm infants. In S.L. Feetham, S.B. Meister, J.M. Bell, \& C.L. Gilliss (Ed.), The nursing of families: Theory/research education/practice (pp. 9098). Newbury Park: Sage. McCubbin, M.A. (1993). Family stress theory and the development of nursing knowledge about family adaptation. In Feetham, S.L., Meister, S.B., Bell, J.M. \& Gilliss, C.L., (Ed.), The nursing of families: Theory/research/education/practice (pp. 46-45) Newbury Park: Sage.

McCubbin, M.A. \& McCubbin, H.I. (1991). Family stress theory and assessment: The resiliency model of family stress, adjustment and adaptation. In H.I. McCubbin \& A.I. Thompson, (Ed.), Family assessment inventories for research and practice (pp. 3-32). Madison: University of Wisconsin.

McCubbin, M.A. \& McCubbin, H.I. (1993). Families coping with illness: The resiliency model of family stress, adjustment and adaptation. In C.B. Danielson, B. HamelBissel, P. Winstead-Fry, (Ed.), Families, health \& 
illness: Perspectives on coping and intervention (pp. 2164). St. Louis: Mosby.

McCubbin, H.I., Mccubbin, M.A. \& Thompson, A.I. (1993). Resiliency in families: The role of family schema and appraisal in family adaptation to crisis. In T.H. Brubaker (Ed.), Family relations: Challenges for the future (pp. 153-177). Newbury Park: Sage. Mccubbin, H.I., \& Patterson, J.M. (1983). The family stress process: The double ABCX model of adjustment and adaptation. In H.I. McCubbin, M.B. Sussman \& J.M. Patterson (Ed.), Social stress and the family (pp. 7-37). New York: Haworth.

Mccubbin, H.I., \& Patterson, J.M. (1991). FILE: Family inventory of life events and changes. In H.I. Mccubbin \& A.I. Thompson, (Ed.), Family assessment inventories for research and practice (pp. 81-100). Madison: University of Wisconsin.

Mccubbin, H.I., Patterson, J.M. \& Wilson, I.R. (198I) .

FILE: Family inventory of life events. In D.H. Olson, H.I. McCubbin, H. Barnes, A. Larsen, M. Muxen, M. Wilson (Eds.), Family inventories (pp. 105-127). St. Paul: University of Minnesota. Mercer, R.T. (1981). A theoretical framework for studying factors that impact on the maternal role. Nursing Research, $\underline{30}, 73-77$. 
Mercer, R.T., \& Ferketich, S. (1988). Stress and social support as predictors of anxiety and depression during pregnancy. Advances in Nursing Science, 11, 26-39.

Mercer, R.T., \& Ferketich, S.I. (1990). Predictors of family functioning eight months following birth. Nursing Research, $\underline{39}(2), 76-82$.

Mercer, R.T., Ferketich, S.L., DeJoseph, J. May, K.A.\& Sollid, D. (1988). Effects of stress on family functioning during pregnancy. Nursing Research, 37, 268275.

Nichols, F.H. (1988). Postpartum adaptation scale. Wichita, KS. The wichita State University.

Norusis, M.J. (1993). SPSS for Windows. [Computer program] Chicago: SPSS Inc.

Nunnally, J.C. (1978). Psychometric Theory. New York: McGraw-Hill.

Olson, D.H. (1989). Circumplex model of family systems VIII: Family assessment and intervention. In D.H. Olson, C.S. Russell, and D.H. Sprenkle (Eds.), Circumplex Model: Systemic assessment and treatment of families (pp. 3-20) New York: Haworth. Olson, D.H., Lavee, Y., \& McCubbin, H.I. (1988). Types of families and family responses to stress across the family life cycle. In D.M. Klien and J. Aldous (Ed.), Social stress and family development (pp. 28-65) New York: Guilford. 
Olson, D., Portner, J., \& Bell. (1981). FACESII. St. Paul, MN : University of Minnesota.

Olson, D.H., \& Tiesel, J. (1991). FACESII: Linear scoring and interpretation. St. Paul, MN: University of Minnesota.

Pittman, J.F., \& Lloyd, S.A. (1988). Quality of family life, social support and stress. Journal of Marriage and the Family, 50(1), 53-67.

Pridham, K.F. (1987). The meaning for mothers of a new infant: Relationship to maternal experience. MaternalChild Nursing Journal, 16, 103-122.

Rubin, R. (1967). Attainment of the maternal role: Part I the process. Nursing Research, 34, 198-204.

Rubin, R. (1984). Maternal identity and the maternal

experience. New York: Springer.

Schroeder, L.D., Sjoquist, D.L., \& Stephen, P.E. (1986).

Understanding regression analysis. Newbury Park: Sage Stainton, M.C. (1989). The perinatal family. In C.L. Gilliss, B.L. Highley, B.M. Roberts, \& I.M. Martinson (Ed.), Toward a science of family nursing (pp. 199-213). Menlo Park, CA: Addison-Wesley. Styles, M.M. (1990). Challenges for nursing in this new decade. The American Journal of Maternal child Nursing, 15, $347-352$. 
Tinsley, H.E.A., \& Tinsley, D.J. (1987). Uses of factor analysis in counseling psychology research. Journal of Counseling Psychology, 34, 414-424.

Tulman, L., \& Fawcett, J. (1988). Return of functional ability after childbirth. Nursing Research, 37, 77-81. Turner, R.J., \& Avison, W.L. (1985). Assessing risk factors for problem parenting: The significance of social support. Journal of Marriage and the Family, 47, 881-892. Ventura, J.N. (1986). Parent coping, a replication. Nursing Research, $35(2), 77-79$.

Wakefield, R.A. (1984). The changing American family. Futurist, $17(12), 17-18$.

Walker, L.O., Crain, H. \& Thompson, E. (1986). Maternal role attainment and maternal identity in the postpartum period: Stability and change. Nursing Research, 35, 6871.

Waltz, C., \& Bausell, R.B. (1981). Nursing research: Design statistics and computer analysis. Philadelphia: Davis. Waltz, C.F., Strickland, O.L., \& Lenz, E.R. (1986).

Measurement in nursing research. Philadelphia: Davis. Weinert, C. (1987). A social support measure: PRQ85. Nursing Research, 36(5), 273-277. Weinert, C., \& Tilden, V.P. (1990). Measures of social support: Assessment of validity. Nursing Research, $\underline{39}(4), 212-216$. 
Whall, A. L., \& Fawcett, J. (1991). Family theory

development in nursing: state of the science and art.

Philadelphia: Davis.

Reproduced with permission of the copyright owner. Further reproduction prohibited without permission. 
Appendix A

Description of The Sample by Race, Marital status,

Obstetrical History, and Infant Feeding Method

of Sample Mothers

\begin{tabular}{|c|c|c|}
\hline Variable & Frequency & Valid Percent \\
\hline Race - Caucasian & 85 & 97.7 \\
\hline Hispanic & 2 & 2.3 \\
\hline \multicolumn{3}{|l|}{ Marital Status } \\
\hline single & 77 & 4.7 \\
\hline Married & 4 & 89.5 \\
\hline $\begin{array}{l}\text { Living with } \\
\text { partner }\end{array}$ & 5 & 5.8 \\
\hline \multicolumn{3}{|l|}{ Pregnancies } \\
\hline One & 48 & 55.8 \\
\hline Two & 25 & 29.1 \\
\hline Three & 9 & 10.5 \\
\hline Four & 2 & 2.3 \\
\hline Five & 1 & 1.1 \\
\hline $\operatorname{six}$ & 1 & 1.1 \\
\hline \multicolumn{3}{|l|}{ Live Births } \\
\hline one & 66 & 76.7 \\
\hline Two & 18 & 20.9 \\
\hline Three & 1 & 1.2 \\
\hline Four & 1 & 1.2 \\
\hline Breast Feeding & 66 & 75.9 \\
\hline
\end{tabular}


Description of Sample by Age, Income Category, and Education

\begin{tabular}{lccl}
\hline Variable & Range & Mean & SD \\
\hline Age & $19-39$ & 28.6 & 5.6 \\
Mother & $21-48$ & 32 & 6.6
\end{tabular}

Years Education

$\begin{array}{llll}\text { Mother } & 11-20 & 14.9 & 2.28 \\ \text { Other } & 10-25 & 14.9 & 2.77\end{array}$

$\begin{array}{llll}\text { Annual Family } & \downarrow \$ 15,000 & \$ 35,000 & \$ 30,000 \\ \text { Income Category* } & \uparrow \$ 80,000 & \$ 39,999 & \end{array}$

*Note $37.4 \%$ of the sample stated their annual family income below $\$ 25,000$ annually 
Appendix B

Prenatal Demographic Surveys

Mother:

Here are a few questions about yourself.

Q - 1 . In what year were you born?

Q - 2. Your gender.

1 WOMAN

2 MAN

Q - 3. Which of the following best describes your racial or ethnic identification?

1 CAUCASIAN / WHITE

2 AFRO-AMERICAN

3 HISPANIC / MEXICAN AMERICAN

4 ASIAN AMERICAN

5 NATIVE AMERICAN / INDIAN

6 OTHER (please specify)

Q - 4. What is the Total number of years of school you have completed (include grade and high school as well as college or vo-tech)? __ Number of Years.

Q - 5. What is the highest degree you have earned?

1 HIGH SCHOOL DIPLOMA

2 GED

3 ASSOCIATE ARTS DEGREE

4 BACHELORS DEGREE

5 MASTERS DEGREE

6 DOCTORAL DEGREE

7 VOCATIONAL TRAINING CERTIFICATE

8 NO DEGREE 
Q - 6. How many children live IN YOUR HOUSEHOLD at this time? NUMBER OF CHILDREN LIVING HERE

AGE OF OLDEST CHILD
AGE OF SECOND CHILD
AGE OF THIRD CHILD
AGE OF FOURTH CHILD
AGE OF YOUNGEST CHILD

GENDER OF OLDEST CHILD
GENDER OF SECOND CHILD
GENDER OF THIRD CHILD
GENDER OF FOURTH CHIID
GENDER OF YOUNGEST CHILD

Q - 7. What is your present marital status?

$\begin{array}{ll}1 & \text { MARRIED } \\ 2 & \text { DIVORCED } \\ 3 & \text { SEPARATED } \\ 4 & \text { WIDOWED } \\ 5 & \text { NEVER MARRIED } \\ 6 & \text { COMMON-IAW } \\ 7 & \text { LIVING TOGETHER }\end{array}$

Q - 8. How long have you been in your present marital status? NUMBER OF YEARS

Q - 9. Counting all sources of income, including wages, interest, welfare payments, and gifts, etc., what was your total family income during 1991? (CIRCLE one number)

$\begin{aligned} I & \text { LESS THAN } \$ 15,000 \\ 2 & \$ 15,000 \text { TO } \$ 19,000 \\ 3 & \$ 20,000 \text { TO } \$ 24,999 \\ 4 & \$ 25,000 \text { TO } \$ 29,000 \\ 5 & \$ 30,000 \text { TO } \$ 34,999 \\ 6 & \$ 35,000 \text { TO } \$ 39,999 \\ 7 & \$ 40,000 \text { TO } \$ 44,999 \\ 8 & \$ 45,000 \text { TO } \$ 49,999 \\ 9 & \$ 50,000 \text { TO } \$ 54,999 \\ 10 & \$ 55,000 \text { TO } \$ 59,999 \\ 11 & \$ 60,000 \text { TO } \$ 64,999 \\ 12 & \$ 65,000 \text { TO } \$ 69,999 \\ 13 & \$ 70,000 \text { TO } \$ 74,999 \\ 14 & \$ 75,000 \text { TO } \$ 79,999 \\ 15 & \text { OVER } \$ 80,000\end{aligned}$

Q - 10. What relationship, to you, is the significant other who is also participating in this study?

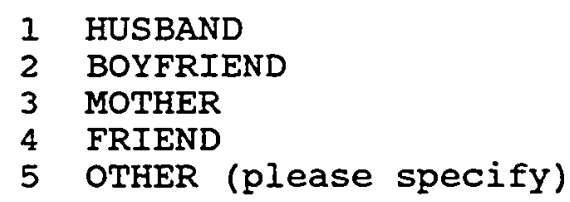


Q - 11. What is the relationship of your significant other to this baby?

\author{
1 FATHER \\ 2 GRANDMOTHER \\ 3 GRANDFATHER \\ 4 OTHER (please specify)
}

$Q-12$. What is your expected date of delivery? (please fill in all three)

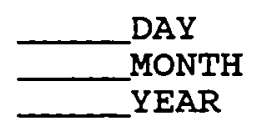

Q - 13. How many times have you been pregnant? (please include this pregnancy) TOTAL NUMBER OF PREGNANCIES

Q - 14. How many live born children do you have? TOTAL NUMBER OF LIVE BORN CHILDREN

Q - 15. Are you currently employed?
1 YES
2 NO

Q - 16. Will you have time off after the birth of the baby? $\begin{array}{ll}1 & \text { YES } \\ 2 & \text { NO }\end{array}$

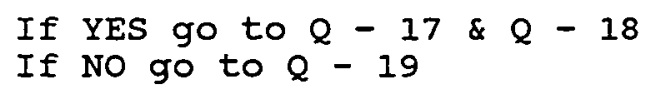

$Q$ - 18. How much time off do you plan to take after the baby is born?
1 ONE DAY
2 TWO - FIVE DAYS
3 ONE - TWO WEEKS
4 TWO - FOUR WEEKS
5 FOUR - SIX WEEKS
6 OVER SIX WEEKS 
Q - 19. Would you like a summary of this study?

$$
1 \text { YES }
$$

2 NO

Reproduced with permission of the copyright owner. Further reproduction prohibited without permission. 
Significant other

Q - 1 . In what year were you born?

$Q-2$. Your gender.

1 WOMAN

2 MAN

Q - 3. Which of the following best describes your racial or ethnic identification?

1 CAUCASIAN / WHITE

2 AFRO-AMERICAN

3 HISPANIC / MEXICAN AMERICAN

4 ASIAN AMERICAN

5 NATIVE AMERICAN / INDIAN

6 OTHER (please specify)

Q - 4. What is the TOTAL number of years of school you have completed (include grade and high school as well as college or vo-tech)? __ Number of Years.

Q - 5. What is the highest degree you have earned?

1 HIGH SCHOOI DIPLOMA

2 GED

3 ASSOCIATE ARTS DEGREE

4 BACHELORS DEGREE

5 MASTERS DEGREE

6 DOCTORAL DEGREE

7 VOCATIONAL TRAINING CERTIFICATE

8 NO DEGREE

Q - 6. How many children live IN YOUR HOUSEHOLD at this time? NUMBER OF CHILDREN IIVING HERE

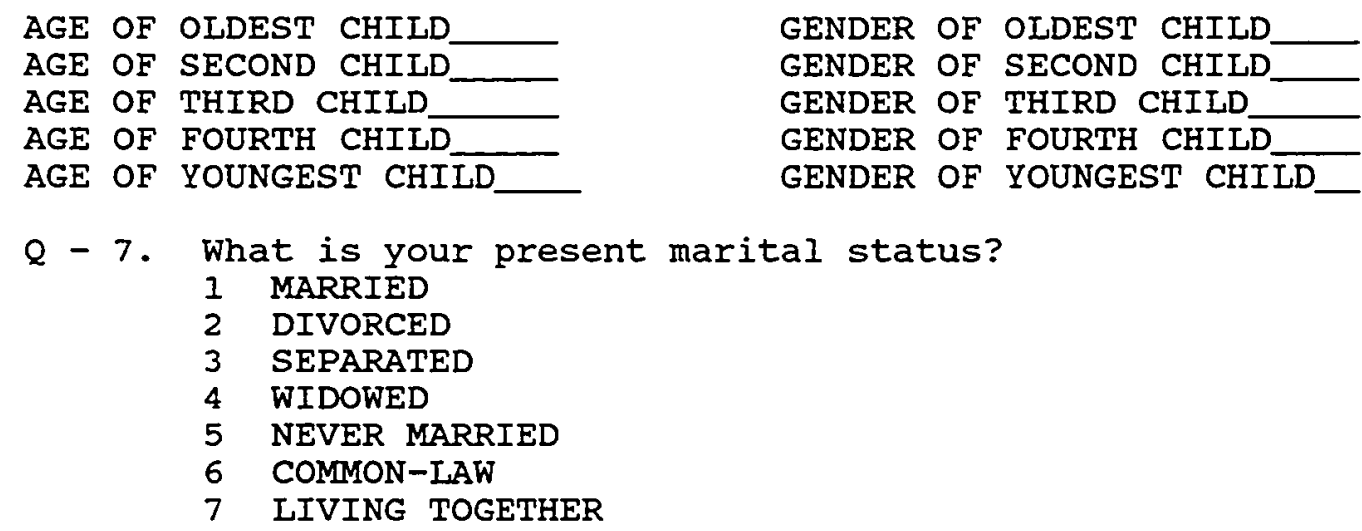


$Q$ - 8. How long have you been in your present marital status? NUMBER OF YEARS

$Q$ - 9. Counting all sources of income, including wages, interest, welfare payments, and gifts, etc., what was your total family income during 1991? (CIRCLE one number)

$\begin{aligned} 1 & \text { LESS THAN } \$ 15,000 \\ 2 & \$ 15,000 \text { TO } \$ 19,000 \\ 3 & \$ 20,000 \text { TO } \$ 24,999 \\ 4 & \$ 25,000 \text { TO } \$ 29,000 \\ 5 & \$ 30,000 \text { TO } \$ 34,999 \\ 6 & \$ 35,000 \text { TO } \$ 39,999 \\ 7 & \$ 40,000 \text { TO } \$ 44,999 \\ 8 & \$ 45,000 \text { TO } \$ 49,999 \\ 9 & \$ 50,000 \text { TO } \$ 54,999 \\ 10 & \$ 55,000 \text { TO } \$ 59,999 \\ 11 & \$ 60,000 \text { TO } \$ 64,999 \\ 12 & \$ 65,000 \text { TO } \$ 69,999 \\ 13 & \$ 70,000 \text { TO } \$ 74,999 \\ 14 & \$ 75,000 \text { TO } \$ 79,999 \\ 15 & \text { OVER } \$ 80,000\end{aligned}$

Q - 10. What is your relationship to the mother to be?

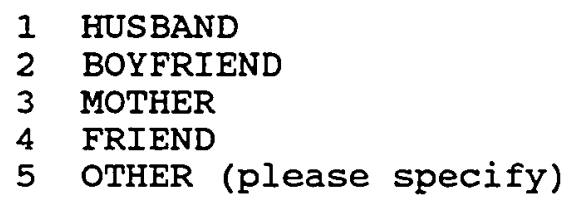

Q - 11. What is your relationship to this baby?

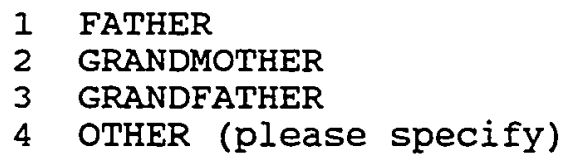

Q - 12. Are you currently employed?

$$
\begin{array}{ll}
1 & \text { YES } \\
2 & \text { NO }
\end{array}
$$

Q - 13. Will you have time off after the birth of the baby?

$$
\begin{aligned}
& 1 \text { YES } \\
& 2 \text { NO } \\
& \quad \text { If YES go to } Q-14 \& Q-15 \\
& \text { If NO go to } Q-16
\end{aligned}
$$


Q - 14. Time off after baby's birth will be paid?
1 YES
2 NO

Q - 15. How much time off do you plan to take after the baby is born?
1 ONE DAY
2 TWO - FIVE DAYS
3 ONE - TWO WEEKS
4 TWO - FOUR WEEKS
5 FOUR - SIX WEEKS
6 OVER SIX WEEKS

Q - 16. Would you like a summary of this study?
1 YES
2 NO 


\section{Appendix C \\ Postbirth Demographic Surveys}

Mother

Now here are some questions about you and the baby.

Q - 1. What day did you deliver? (please fill in all three)

\begin{tabular}{l} 
DAY \\
\hline MONTH \\
\hline YEAR
\end{tabular}

Q - 2. What is the gender of your baby?

GIRI

Q - 3. How much did your baby weigh at birth?

POUNDS

OUNCES

Q - 4. Are you breast feeding your baby?

1 YES

2 NO

Q - 5. Are you currently employed?

1 YES

2 NO

Q - 6. Did you have time off after the birth of your baby?

1 YES

2 NO

Q - 7. Was your time off after your baby's birth paid?

1 YES

2 NO

92 


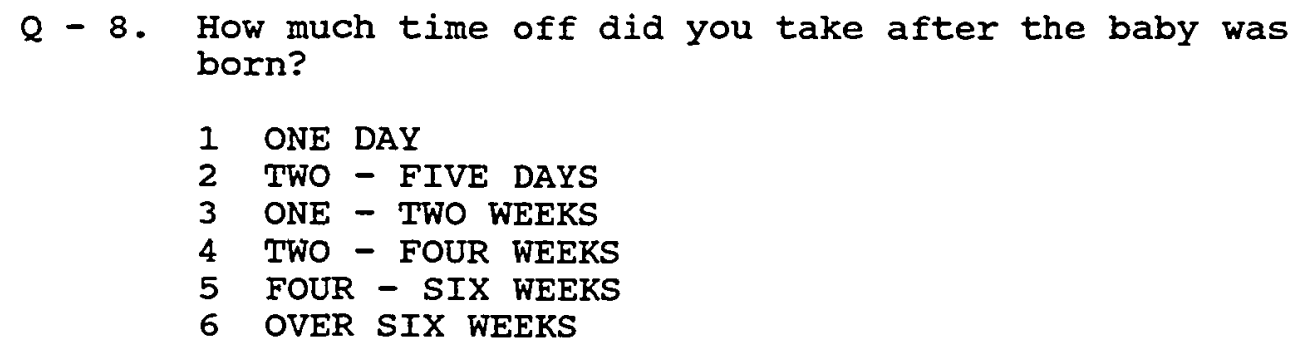


Significant other

Now here are some questions about you and the baby.

Q - 1 . In what year were you born?

Q - 2. What is the TOTAL number of years of school you have completed (include grade and high school as well as college or vo-tech)? Number of Years.

Q - 3. What is your relationship to this baby?

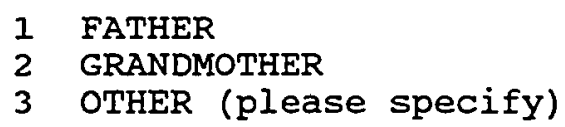

1 FATHER

2 GRANDMOTHER

3 OTHER (please specify)

Q - 5. Are you currently employed?

1 YES

2 NO

Q - 6. Did you have time off after the birth of the baby?

1 YES

2 NO

Q - 7. Was your time off after your baby's the paid?

1 YES

2 NO

Q - 8. How much time off did you take after the baby was born?
1 ONE DAY
2 TWO - FIVE DAYS
3 ONE - TWO WEEKS
4 TWO - FOUR WEEKS
5 FOUR - SIX WEEKS
6 OVER SIX WEEKS 


\section{Appendix D}

Sample Items From The Family Inventory of

Life Events and Changes (FILE)

\begin{tabular}{ccc}
\hline DID THE CHANGES HAPPEN & \\
IN YOUR FAMILY? & $\begin{array}{c}\text { During Last } \\
\text { I2 Months }\end{array}$ & $\begin{array}{l}\text { Before Last } \\
12 \text { months }\end{array}$ \\
\hline
\end{tabular}

I. INTRA-FAMILY STRAINS

1. Increase of husband/father's time away from home.

2. Increase of wife/mother's time away from home.

II. MARITAL STATUS

1. Spouse/parent was separated or divorced.

2. Spouse/parent has an "affair".

III. PREGNANCY AND CHILDBEARING STRAINS

1. Spouse had an unwanted or difficult pregnancy.

2. An unmarried member became pregnant.

IV. FINANCE AND BUSINESS STRAINS

1. A member started a new business.

2. Purchased or built a home.

\begin{tabular}{|c|c|c|}
\hline YES & NO & YES \\
\hline & & \\
\hline & & \\
\hline & & \\
\hline & & \\
\hline & & \\
\hline & & \\
\hline & & \\
\hline & & \\
\hline & & \\
\hline & & \\
\hline & & \\
\hline & & \\
\hline & & \\
\hline & & \\
\hline & & \\
\hline & & \\
\hline
\end{tabular}

95 
V. WORK-FAMILY TRANSITIONS AND STRAINS

1. A member lost or quit a job.

2. Decrease in satisfaction with job/career.

VI.ILINESS AND FAMILY CARE STRAINS

1. Parent/spouse became seriously ill or injured.

2. Close relative or friend of the family became seriously ill.

VII. LOSSES

1. A parent/spouse died.

2. A child member died.

VII. TRANSITIONS "IN AND OUT"

1. A member was married.

2. Young adult member left home.

IX. FAMILY LEGAL VIOLATIONS

1. A member went to jail or juvenile detention.

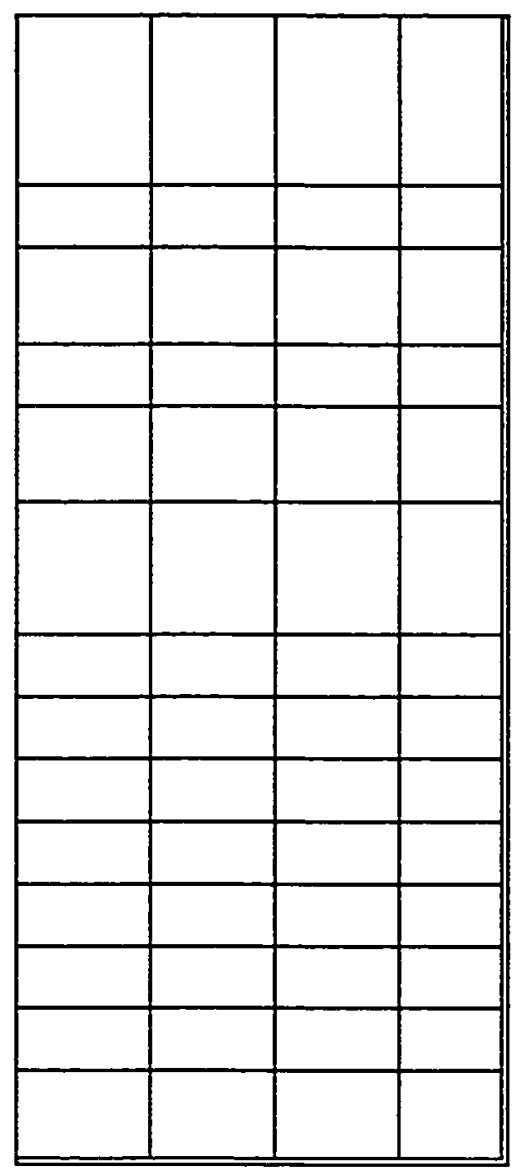

Copyright McCubbin, H.I., 1981. Permission to use granted May, 1992. 


\section{Appendix E}

Sample Items From PRQ85 Part 2

Q - 11. Below are some statements with which some people agree and others disagree. Please read each statement and CIRCLE the response most appropriate for you. There is no right or wrong answer.

$\begin{array}{lll}1 & \text { STRONGLY } & \text { DISAGREE } \\ 2 & \text { DISAGREE } & \\ 3 & \text { SOMEWHAT } & \text { DISAGREE } \\ 4 & \text { NEUTRAL } & \\ 5 & \text { SOMEWHAT } & \text { AGREE } \\ 6 & \text { AGREE } & \\ 7 & \text { STRONGLY } & \text { AGREE }\end{array}$

\section{Statements}

a. There is someone I feel close to who makes me feel secure.....................122 344567

b. I belong to a group in which I feel

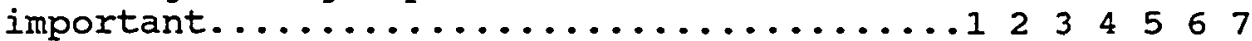

c. People let me know that I do well at my

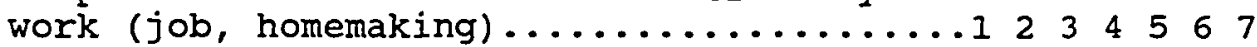

d. I can't count on my relatives and friends to help me with problems..............1 2344567

e. I have enough contact with the person who makes me feel special.............1 234567

f. I spend time with others who have the

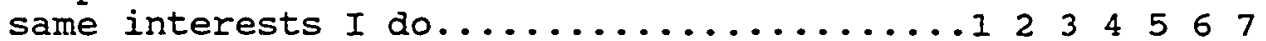

g. There is little opportunity in my life to

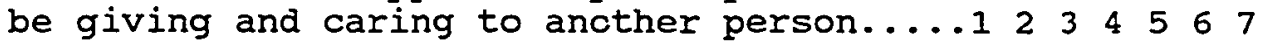

Copyright by Brandt and Weinert, 1985. Permission to use granted september, 1991 


\section{Appendix F \\ Sample Items From the Postpartum Adaptation Scale}

These statements have been made by mothers to describe how they feel following childbirth. Do not spend much time on any one statement but give the answer that seems to describe how you generally feel. Read each statement and then CIRCLE the number that BEST describes your feelings DURING THE PAST WEER INCLUDING TODAY.

\begin{tabular}{lll}
\hline & 1 & DEFINITELY NO \\
& 2 NO (May happen once in a wile) \\
& 3 Yes (May happen some of the time) \\
4 & DEFINITELY YES \\
STATEMENTS MADE FOLLOWING CHILDBIRTH & \\
\hline
\end{tabular}

Q - 1. I get along well with my mother most

of the time.................... 234

$Q$ - 2. I often forget to eat.............. 2 2 34

Q - 3. I often call my baby by name.......... 2 34

Q - 4. My husband/partner seems to compete with the baby for attention........... 234

Q - 5. It is a waste of time to play games

with my baby.................... 234

Q - 6. I often have diarrhea (frequent

watery bowel movements)............ 234

$Q$ - 7. I like being a mother.............. 2 34

Q - 8. I cry when the baby cries........... 2 2 34

Q - 9. My baby always cries/fusses when I need to do something................. $23{ }^{2} 4$

Copyright Nichols, F., 1988. Permission to use granted September, 1991. 
Appendix G

Sample Items For The Family Cohesion and Adaptability

\section{Evaluation Scale (FACESII)}

$\begin{array}{ll}1 & \text { ALMOST NEVER } \\ 2 & \text { ONCE IN A WHILE } \\ 3 & \text { SOMETIMES } \\ 4 & \text { FREQUENTLY } \\ 5 & \text { ALMOST ALWAYS }\end{array}$

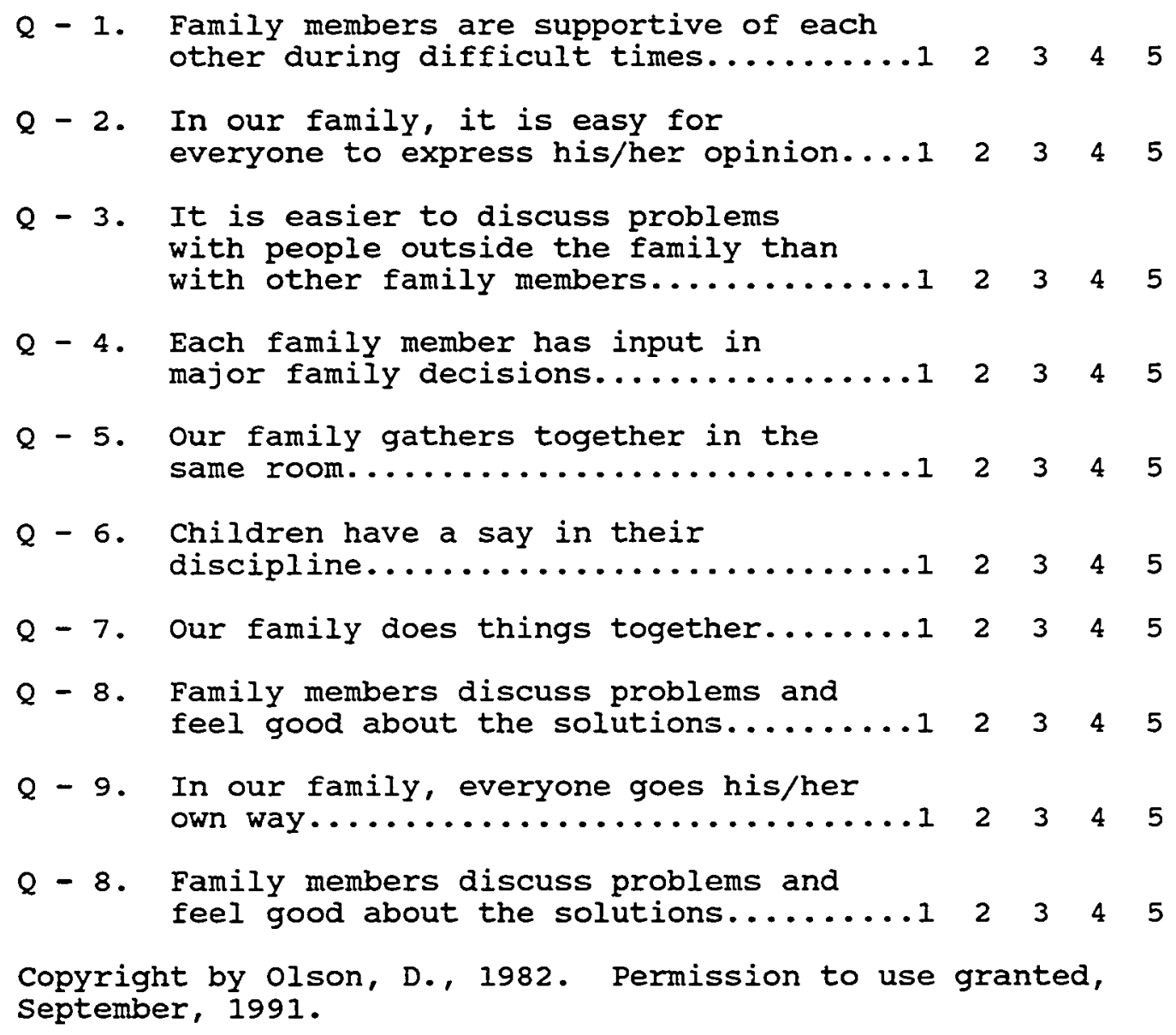


Appendix I

Mother's consent Form

\section{Maternal Adaptation Study}

As nurses, we are interested in how we can better support you following childbirth. You are being asked to participate in a study that will help us to identify several things about families after a new baby is added. This research will examine ways in which family stress and support influence the new mother's adjustment to motherhood and the well-being of the family. The information will help nurses and other members of the health care system design programs and structure care to better serve the needs of families like yours.

You will be asked to comment on your feelings both now and following the birth of your baby. The risk involved is minimal, only the sacrifice of your time in filling out the questionnaires. Questions asked relate to stresses, changes, and supports and feelings regarding your family. If at any time you have questions or concerns related to the study, call the nurse researcher collect. Should you become distressed as a result of participation in the study, you may at your request be referred to a counseling agency. Following the birth, you will complete another booklet of questions similar to the one you will complete today. This booklet will contain an additional questionnaire about how you feel in relation to your baby's birth and motherhood. Before signing this consent and at any time during the study, you may ask the researcher or research assistant any questions you wish regarding the study. You may also refuse to answer any of the questions in the booklets you receive. This is a privately funded study and participation in the study will not cost you anything nor will you be paid for your participation. If you or your baby develop medical complications or the baby is born before the eighth month of pregnancy, you are no longer eligible to participate in the study.

If you agree to participate, the following will take place today:

1. You will be asked to identify the person over 18 living in your household that is the most involved

101 
with your pregnancy and will be influenced the greatest when your baby is born.

2. You will be asked to carefully read and complete this consent form. After the form is signed you will receive a copy.

3. A nurse researcher or research assistant will ask you to complete a booklet containing four questionnaires. This process will take about 20 to 30 minutes.

4. You will receive a card with the name, address, and phone number of the nurse researcher conducting the study.

5. You will receive an addressed, postpaid card. Please write the delivery date on the card and return it to the researcher within five days of your baby's birth.

Five to six weeks after your baby's birth a second packet of materials will be mailed to you. This packet will contain the following:

1. One booklet for the new mother to complete containing questionnaires similar to those completed today and one additional questionnaire related to your adjustment to motherhood. This booklet will take 35 to 55 minutes to complete.

2. One booklet for your family member containing four questionnaires similar to those filled out at the first meeting. This will take approximately 20 to 30 minutes.

3. A stamped envelope addressed to the nurse researcher.

Code numbers have been assigned to the forms. Your responses to questions and the completed forms will be kept confidential. All completed forms will be identified with the code number assigned to you. Your name and address will be kept only until the study is completed. If requested, a summary of the results will be mailed to you. Upon completion of the study, all names, addresses, and phone numbers will be destroyed. Projected completion date for this project is April 1993. In the event we fail to receive the return packets you will receive a telephone reminder, one time, 10-14 days after the packets have been mailed to you. You may withdraw from the study at any time. Refusal to participate in or withdrawal from the study will not, in 
any way, affect your relationship with your health care providers.

The principle investigator and research assistants will treat your identity with professional standards of confidentiality. The findings of this study will be reported in numerical averages and group findings (thereby ensuring that participants will remain anonymous). The information obtained in this study may be published in professional reports and journals but your identity will not be revealed. There is no agreement between the subjects and the researcher other than what is stated in this form. 
AUTHORIZATION: I, the undersigned, understand the above explanations and on that basis, I give consent to my voluntary participation in this research. I understand that I may later refuse to participate or that I may withdraw from the study at any time. I have received a copy of this consent for, for my own records.

Signature of Subject

Date

Location (e.g. Great Falls, MT)

Signature of Principle Researcher Date

Signature of witness

Date

Reproduced with permission of the copyright owner. Further reproduction prohibited without permission. 


\section{Appendix J \\ Significant Other's consent Form}

\section{Maternal Adaptation Study}

As nurses, we are interested in how we can better support you following childbirth. You are being asked to participate in a study that will help us to identify several things about families after a new baby is added. This research will examine ways in which family stress and support influence the new mother's adjustment to motherhood and the well-being of the family. The information will help nurses and other members of the health care system design programs and structure care to better serve the needs of families like yours.

You will be asked to comment on your feelings both now and following the birth of your baby. The risk involved is minimal, only the sacrifice of your time in filling out the questionnaires. Questions asked relate to stresses, changes, and supports and feelings regarding your family. If at any time you have questions or concerns related to the study, call the nurse researcher collect. Should you become distressed as a result of participation in the study, you may at your request be referred to a counseling agency. Before signing this consent and at any time during the study, you may ask the researcher or research assistant any questions you wish regarding the study. You may also refuse to answer any of the questions in the booklets you receive. This is a privately funded study and participation in the study will not cost you anything nor will you be paid for your participation. If the expectant mother or baby develop medical complications or the baby is born before the eighth month of pregnancy you are no longer eligible to participate in the study.

You have been chosen to participate in this study because you have been identified by the expectant mother as the adult person living in her household most involved with this pregnancy and most influenced by the birth of this baby. If you agree to participate the following will take place today: 
1. You will be asked to carefully read and complete this consent form. After the form is signed you will receive a copy.

2. A nurse researcher or research assistant will ask you to complete a booklet containing four questionnaires. This process will take about 20 to 30 minutes.

3. You will receive a card with the name, address, and phone number of the nurse researcher conducting the study.

Five to six weeks after the baby's birth a second packet of materials for you and the new mother will be mailed. This packet will contain the following:

1. One booklet for the new mother to complete containing questionnaires similar to those completed today and one additional questionnaire related to your adjustment to motherhood. This booklet will take 35 to 55 minutes to complete.

2. One booklet for you containing four questionnaires similar to those filled out at the first meeting. This will take approximately 20 to 30 minutes.

3. A stamped envelope addressed to the nurse researcher.

Code numbers have been assigned to the forms. Your responses to questions and the completed forms will be kept confidential. All completed forms will be identified with the code number assigned to you. Your name and address will be kept only until the study is completed. If requested, a summary of the results will be mailed to you. Upon completion of the study all names, addresses, and phone numbers will be destroyed. Projected completion date for this project is April 1993. In the event we fail to receive the return packets, you will receive a telephone reminder, one time, 10-14 days after the packets have been mailed to you. You may withdraw from the study at any time. Refusal to participate in or withdrawal from the study will not, in any way, affect your relationship with your health care providers. 
The principle investigator and research assistants will treat your identity with professional standards of confidentiality. The findings of this study will be reported in numerical averages and group findings (thereby ensuring that participants will remain anonymous). The information obtained in this study may be published in professional reports and journals but your identity will not be revealed. There is no agreement between the subjects and the researcher other than what is stated in this form. 
AUTHORIZATION: $I$, the undersigned, understand the above explanations and on that basis, I give consent to my voluntary participation in this research. I understand that I may later refuse to participate or that I may withdraw from the study at any time. I have received a copy of this consent for, for my own records.

Signature of Subject $\quad$ Date

Location (e.g. Great Falls, MT)

Signature of Principle Researcher Date

Signature of Witness Date 
Appendix K

Participant Information Sheet

Name:

Address:

City

State_ zip

Phone (_) _ _ _

I would like a summary of the findings or this study mailed to me upon study completion.

Yes

No

Code Number 
Appendix L

Letter of Explanation

Dear (Name),

It has been six weeks since the birth of your baby. Enclosed is the packet contains the following:

1. A booklet for the new mother to complete. This booklet will take 35 to 55 minutes to complete.

2. A booklet for the significant other who participated when we first met before the birth of the baby. This will take approximately 20 to 30 minutes to complete.

3. A stamped envelope addressed to he nurse researcher.

Please read the directions carefully and complete each form accordingly. The booklets are labeled mother and family member to avoid confusion. After both booklets are complete, place them in the enclosed self-addressed and stamped envelope and return them by mail to the researcher. If the questionnaires are not received within ten (10) days after they are mailed to you, the researcher will telephone. The purpose of this call is to remind you to send back your forms and see if you have any questions regarding the study.

If you have any questions regarding completion of the forms or the study itself, please call either myself collect or the research assistant in your area. Your participation in this study is greatly appreciated. As an expression of my gratitude a small gift will be mailed to you upon completion of these questionnaires. If you requested a summary of the findings, one will be mailed to you when the study is complete. Thank you for your time and help in the completion of this study.

Sincerely,

Constance $\mathrm{H}$ Hansen $\mathrm{MN}$, DNSc(C), RN

Associate Professor, College of Nursing

Montana State University

Phone: (406) 452-0711 (H)

(406) 455-5611 (0) 